\title{
Impact of chemical structure of individual fatty acid esters on combustion and emission characteristics of diesel engine
}

Lei Zhu $^{\mathrm{a}, *}$, C.S. Cheung ${ }^{\mathrm{b}}$, Zhen Huang ${ }^{\mathrm{a}}$

${ }^{a}$ Key Laboratory for Power Machinery and Engineering of M.O.E, Shanghai Jiao Tong University, Shanghai, P.R. China

${ }^{b}$ Department of Mechanical Engineering, The Hong Kong Polytechnic University, Hong Kong SAR, P.R. China

Corresponding author:

E-mail address: tonyzhulei@gmail.com_tonyzhulei@sjtu.edu.cn (Lei Zhu)

Tel: + 86-3420 5949; Fax: +86-3420 5949

* Corresponding address: School of Mechanical Engineering, Shanghai Jiao Tong University, Shanghai, P.R. China 


\section{Abstract}

The effects of fatty acid chain length, number of double bonds and alcohol moiety chain length on combustion and emission characteristics were investigated. With the increase of carbon chain length of methyl ester, $\mathrm{HC}, \mathrm{CO}$ and smoke emissions increase. The particle number concentration of nucleation mode decrease and accumulation mode increases with carbon chain length. The diameter of primary particle increases with carbon chain length. The double bonds of methyl ester are strongly correlated with $\mathrm{CO}, \mathrm{HC}$, nucleation mode and accumulation mode particles. The BSFC of unsaturated methyl ester is slightly higher. With increase of alcohol moiety chain length, the start of combustion is advanced, leading to lower premixed combustion, and thus resulting in the higher $\mathrm{HC}, \mathrm{CO}$ and smoke and lower NOx emissions. Ethyl ester generates lower number concentration in nucleation mode, while it has higher number concentration in accumulation mode. The primary particle size of ethyl ester is larger than that of methyl ester. These results indicate that molecular structure of ester has great influence in combustion and emission characteristics. The composition of biodiesel could be modified and optimized during production process through new techniques or various feedstocks in order to improve combustion and emission of biodiesel.

Keywords: Fatty acid ester; Molecular structure; NOx; Soot; Particle size distribution; 


\section{Introduction}

In recent years, in order to reduce the reliance on fossil diesel fuel for various applications, there is increasing interest in investigating the potential application of alternative fuels, such as biodiesel or alcohol, to diesel engines [1]. Biodiesel is an alternative diesel fuel consisting of alkyl monoesters of fatty acids derived from vegetable oil, animal fats or waste cooking oil through the transesterification reaction. Due to its similar physical properties to diesel fuel, neat biodiesel or its blends with diesel fuel can be used on diesel engines directly [2]. Many studies have reported that the application of biodiesel in diesel engines could reduce the hydrocarbon ( $\mathrm{HC})$, carbon monoxide (CO) and particulate matter (PM) emissions, while increase nitrogen oxides (NOx) emission, when compared with using diesel fuel [3-6]. All these changes in gaseous emissions are attributed to the effect of oxygen in the ester group $(-\mathrm{COOH})$ in improving combustion. While the reduction of PM emissions is not only attributed to oxygen content in fuel, but also to the lack of aromatics in biofuel molecule.

The typical biodiesel components are saturated and unsaturated fatty acid methyl esters or ethyl esters with 12 to 20 carbon atoms in the carbon chain. However, the compositions vary with the feedstocks. Differences in molecular structure influence the physical and chemical properties of a biodiesel, and hence affect the combustion and emission characteristics during in-cylinder combustion process. The molecular structure of a biodiesel can be characterized by the fatty acid chain length, the degree of unsaturation and the alcohol chain length. 
Various studies have been conducted to investigate the relationship between chemical-physical properties of a biodiesel and its molecular structure. Both moieties, the fatty acid and alcohol had considerable influence on fuel properties [7]. Cetane number, heat of combustion, melting point, and viscosity of neat fatty compounds increase with the increase of chain length and decrease with unsaturation. Fatty acid profile of biodiesel corresponds to that of its feedstock. Most common feedstocks possess fatty acid profiles consisting mainly of five C16 to C18 fatty acids, namely, palmitic, stearic, oleic, linoleic and linolenic acids [8].

Several investigations have been conducted on the influence of biodiesel components on the combustion and emissions characteristics. Jha et al. [9] evaluated the effect of unsaturation level and hydrocarbon chain length on the temperature of open flames. They found that the presence of saturated components and lower carbon chain length components led to higher flame temperatures. Puhan and Nagarajan [10] investigated the effect of biodiesel unsaturated fatty acid on the combustion characteristics and emissions of a single cylinder direct injection diesel engine. They concluded that (a) a biodiesel fuel with more unsaturated fatty acid composition has higher density but lower viscosity; (b) a biodiesel with more unsaturated fatty acid components has lower cetane number, higher activation energy and longer ignition delay period; (c) a biodiesel with more unsaturated biodiesel fuels emits higher HC, CO and smoke emissions; (d) more NO was observed in case of highly unsaturated biodiesel fuel due to longer ignition delay and advanced fuel injection timing; (e) higher gas pressure, higher exhaust gas temperature and 
higher heat release rate were observed in case of highly unsaturated biodiesel. Lapuerta et al. [11] concluded that as the biodiesel fuel became more unsaturated, NOx emissions increased by $10 \%$ and particle mass emissions decreased by $20 \%$. Salamanca et al. [12] investigated the variations in the chemical composition and morphology of soot induced by the unsaturation degree of biodiesel and a biodiesel blend. They found that with an increase in degree of unsaturation in biodiesel, there is increase in smoke opacity, PM, volatile matter content of PM and aliphatic content of PM. However, these studies focused on influence of methyl ester distribution with different types of biodiesel, not on influence of molecular structure with different individual fatty acid ester.

There are very few investigations on the effects of ester molecular structure on engine combustion and emission. Schönborn et al. [13] conducted a series of experiments on a single-cylinder research engine, investigating the influence of the molecular structure on the combustion behavior of eight fatty acid alkyl ester molecules from C12 to C22 and four biodiesel fuels under diesel engine conditions. Experiments were conducted at the same indicated mean effective pressure but no details on the engine load were mentioned. They concluded that (a) increasing fatty acid chain length, increasing saturation and an increase in chain length of the alcohol moiety decrease the ignition delay and thus decrease the fraction of premixed combustion; (b) molecules with shorter fatty acid chains produce more NOx in diesel combustion because of the longer ignition delay of the shorter chain fatty acid molecules; (c) the number of double bonds present in the fatty acid moiety of the 
molecules was strongly correlated with the emission of accumulation mode soot particles; and (d) the specific particulate number concentration of nucleation mode particles correlates well with the boiling points of the individual fatty acid methyl ester molecules. Pourkhesalian et al. [14] investigated the influence of fuel molecular structure on the volatility and oxidative potential of biodiesel particulate matter. They observed that more saturated fuels with shorter carbon chain lengths result in lower particle mass but produce particles that are more volatile and also have higher levels of reactive oxygen species. However, these investigations were conducted at a single engine load and with emphasize on NOx and PM emissions. Moreover, there is lack of comparison on the diameter of primary soot particles formed during combustion of individual fatty acid ester.

The present study further investigates the effects of fatty acid chain length, number of double bonds and alcohol chain length on combustion and emission characteristics of a four cylinders diesel engine. $\mathrm{HC}, \mathrm{CO}$, NOx, smoke opacity, particle size distribution, and diameter of primary soot particle of five individual fatty acid esters were analyzed and compared at the same experimental conditions, two steady engine speeds and four engine loads.

\section{Experimental equipment and procedures}

The experimental set up is shown in Fig. 1. A turbocharged 4-cylinder Cummins direct-injection diesel engine was used in this study. The main specifications of the engine are shown in Table 1. The original test engine was calibrated by standard diesel fuel. An eddy-current dynamometer was coupled with the engine for 
measuring and adjusting the speed and torque of the engine. In this study, in-cylinder pressure signals were sampled and used to calculate the heat release rate and analyze the combustion process. The cylinder pressure was measured by a Kistler piezoelectric sensor type 6056A and the pressure signals were amplified with a Kistler charge amplifier type 5011B. The amplified pressure signals were recorded and analyzed with a combustion analyzer (OSIRIS, Version 4.12.1). A crank-angle encoder was employed for crank-angle signal acquisition at a rate of 360 signals per engine revolution. The gaseous species of engine exhaust were measured by a CAI analyzer (CAI 600). The emission data recorded were $\mathrm{CO}, \mathrm{CO}_{2}, \mathrm{NO}_{\mathrm{x}}$, and THC. Smoke opacity was measured by an opacity meter (AVL 439), with smoke intensity expressed in terms of the extinction coefficient $k$, which increases with the increase of smoke concentration. The particle size distributions were measured with a TSI 3034 SMPS (scanning mobility particle sizer, TSI Inc., Shoreview, MN) within a range of 10-487 $\mathrm{nm}$. The SMPS 3034 is composed of a DMA (differential mobility analyzer) and a TSI 3010 CPC (condensation particle counter). In order to dilute and cool the exhaust sample, the exhaust gas of the engine was diluted with the ambient air by the single staged dilution tunnel firstly, before passing through the SMPS. A valve was set up to adjust the fraction of the exhaust passing through the dilution tunnel. The dilution ratio was calculated with $\mathrm{CO} 2$ concentration in the exhaust before dilution, in the mixture gas after dilution and in the background. The dilution ratio was controlled to maintain around 64. In order to prevent deposition of solid particles and condensation of volatile organics, a temperature controller was used to maintain 
the surface temperature of stainless tube between exhaust pipe and dilution tunnel at $300{ }^{\circ} \mathrm{C}$. The particulate samples for the TEM analysis were collected on $47 \mathrm{~mm}$ quartz filter paper (ADVANTEC Corporation) after dilution at 2000 $/ \mathrm{min}$ and $0.68 \mathrm{MPa}$, and pretreated by the extraction method. The commercial image processing software Image-Pro Plus 6.0 (Media Cybernetics) was used to analyze the TEM images. From the TEM images, about 150 primary particles with clear boundaries were randomly chosen for the primary particle diameter measurement.

Experiments were conducted at a steady engine speed of $1200 \mathrm{r} / \mathrm{min}$ and $2000 \mathrm{r} / \mathrm{min}$ and at engine loads of $0.19 \mathrm{MPa}, 0.28 \mathrm{MPa}, 0.48 \mathrm{MPa}$ and $0.68 \mathrm{MPa}$ respectively, which are the common working conditions. At each engine mode, experiments were carried out for diesel fuel, and each of the fatty acid esters without EGR system. To ensure the repeatability and comparability of the measurements, the cooling water temperature was automatically controlled by a temperature controller to $80^{\circ} \mathrm{C}$, and held to within $\pm 2{ }^{\circ} \mathrm{C}$, while the lubricating oil temperature varied from 90 to $95^{\circ} \mathrm{C}$, depending on the engine load. Data was recorded after the engine was allowed to run for a few minutes until the exhaust gas temperature, lubricating oil temperature, and the cooling water temperature attained their respective steady-state values. All the emissions and combustion pressure were continuously measured for $5 \mathrm{~min}$ and the average results presented. Moreover, for minimizing cross contamination of different fuels with each other, before each test, the engine was allowed to operate with the new fuel for thirty minutes to clean up the fuel system. Each test was repeated twice to ensure that the results are repeatable within the experimental 
uncertainties. The experimental uncertainty has been calculated by the method of Kline and McClintock [15] and Ames et al. [16].

\section{Fuel properties and molecules investigated}

Five fatty acid esters were used to investigate the effects of fatty acid chain length, degree of unsaturation of the fatty acid, and the effect of alcohol chain length on the combustion and emission characteristics of the diesel engine. Due to the higher pour points of methyl palmitate ( $\mathrm{C} 16: 0)$ and methyl stearate (C18:0), it is not possible to test these fuels in the engine in their pure form. Thus, all the fatty acid esters used in this study were blended at $40 \% \mathrm{v} / \mathrm{v}$ with the diesel fuel. The diesel fuel is purchased from common petrol station of China without any biofuel addition. The molecular structures of the fatty acid esters are shown in Fig. 2, and major properties of the fatty acid esters are given in Table 2.

Three sample groups were used to study three distinct aspects of molecular structure. First, the impact of fatty acid chain length was studied using three fully saturated methyl esters different chain lengths. The tested fatty acid esters were methyl laurate (C12:0), methyl palmitate (C16:0), and methyl stearate (C18:0). Second, the effect of fatty acid chain unsaturation was investigated using two fatty acid esters with different degree of unsaturation. The tested fatty acid esters were methyl stearate (C18:0) and methyl oleate (C18:1). Third, the effect of carbon chain length in the alcohol moiety was studied using two fatty acid esters, a methyl and an ethyl ester of oleate. The tested fuels are methyl oleate (C18:1 M) and ethyl oleate (C18:1 E).

\section{Results and discussion}




\subsection{Effect of carbon chain length of fatty acid ester}

Fig. 3 and Fig. 4 show the effect of carbon chain length on the combustion characteristics. Fig. 3 shows the in-cylinder pressures and the heat release rates while the start of combustion and the duration of combustion are shown in Fig. 4. The start of combustion is defined as the beginning of heat release, and the end of combustion is defined as the crank angle where the summated heat release is $95 \%$ of the total heat release. The combustion duration is the time interval from the start of combustion to the end of combustion. Fig. 3 shows that the heat release rates of all the fuels have similar shape, having a premixed combustion phase followed by a diffusion combustion phase. At each test mode, with the increase of carbon chain length, the curves of in-cylinder pressure and heat release rate move further away from the top dead center (TDC), the peak pressure and peak heat release rate decreased while the start of combustion is advanced and the combustion duration is prolonged. With increase in engine load, the differences in combustion characteristics among the fuels maintain similar.

Methyl esters are comprised of straight-chain paraffin and - $\mathrm{COOCH}$. With the increase of carbon chain length, the oxygen content of the methyl ester decreases, which results in lower rate of fuel oxidation and hence longer combustion duration. On the other hand, as can be seen in Table. 2, the fuel viscosity and surface tension increase with carbon chain length, which result in poorer atomization condition, and reduce the quantity of air-fuel mixture in the premixed combustion phase. The shift from premixed combustion towards diffusion combustion will shorten ignition delay 
period and shorten flame lift-off lengths [17]. As shown in the figure 5, the BSFC of methyl esters with different carbon chain length maintain the same level. On one hand, with increase of carbon chain length, the fraction of diffusion combustion increases according to above discussion, leading to the increase of fuel consumption. On the other hand, the low heat value of methyl ester increases with carbon chain length according to Table 2, leading to the decrease of fuel consumption. These conflicting factors act against each other leading to the similar level of BSFC between methyl esters with different carbon chain length.

Fig. 6 and 7 show the gaseous emission and smoke opacity of the diesel engine fueled with methyl esters with different carbon chain lengths at engine speed of $1200 \mathrm{r} / \mathrm{min}$ and $2000 \mathrm{r} / \mathrm{min}$. It is obvious that HC emissions, CO emissions and smoke opacity associated with the methyl esters are lower than those of diesel fuel, while NOx emissions are higher in most of the cases. With the increase of carbon chain length, $\mathrm{HC}, \mathrm{CO}$ and smoke opacity increase while NOx decreases slightly. At $0.68 \mathrm{MPa}$ engine load of $1200 \mathrm{r} / \mathrm{min}, \mathrm{HC}, \mathrm{CO}$ and smoke opacity increase $11 \%, 98 \%$ and $26 \%$ from methyl laurate (C12:0) to methyl stearate (C18:0), while NOx decreases 2\%, which are within the error measurements. The variations of emissions are same with different engine speed. The possible reason is as follows. Thermal mechanism dominates the formation of NOx in biodiesel combustion [4]. Thus the major factors affecting NOx formation are combustion temperature, local oxygen concentration and residence time in the high temperature zone. A methyl ester with longer carbon chain length has higher cetane number, which leads to the shorter ignition delay 
period and longer combustion duration (Fig.3 and Fig. 4). Hence, there is less fuel burned in the premixed stage resulting in lower combustion temperature, leading to higher $\mathrm{HC}$ and $\mathrm{CO}$ emissions and lower NOx emission. On the other hand, more fuel is burned in the diffusion combustion mode, leading to the higher smoke emission [3]. Table 2 shows that the oxygen content in the methyl esters reduces with increasing carbon chain length, which also induces higher $\mathrm{HC}, \mathrm{CO}$ and smoke emissions and lower NOx emission.

With an increase in carbon chain length, there is also an increase in viscosity and surface tension, both of which could worsen the fuel atomization and fuel-air mixing processes, resulting in lower NOx emissions and higher $\mathrm{HC}, \mathrm{CO}$ and smoke emissions. The adiabatic flame temperature is an important factor for thermal formation of NOx. The longer carbon chain length methyl esters give lower adiabatic flame temperatures and hence suppress the formation of NOx [9]. Feng et al.[18] reported that for the same functional ester group (methyl or ethyl), maximum soot volume fractions in diffusion flame increase with the carbon number, which is consistent with the results in this study.

The harmful effect of particle emissions of diesel engines not only depends on its mass concentration, but more importantly also on its size and number concentration. Smaller particles are much easier to diffuse in the ambient air and absorb more hazardous substances, then easier to be breathed into the lungs [3]. Figs. 8 and 9 show the effects of carbon chain lengths on the characteristics of particle number size distribution for engine loads of $0.28 \mathrm{MPa}$ and $0.68 \mathrm{MPa}$ at engine speed of 
$1200 \mathrm{r} / \mathrm{min}$ and $2000 \mathrm{r} / \mathrm{min}$. The size distribution curves of all different fuels show similar bimodal structure, which is composed of a nucleation mode $(\mathrm{Dp}<50 \mathrm{~nm})$ and an accumulation mode ( $D p>50 \mathrm{~nm}$ ). It can be found from the figures that the peak of the curve increases with the decrease of carbon chain length at each test mode. All fuels have higher number concentration at nucleation mode than at accumulation mode. At each test mode, the nucleation particle number concentration decrease with the carbon chain length increase, while accumulation mode increases, especially at high engine load. The variation of accumulation mode is more obvious at engine speed of $1200 \mathrm{r} / \mathrm{min}$.

On one hand, with the increase of carbon chain length, the oxygen content of ester decreases obviously. The lower oxygen content could improve the formation of soot precursor, and then increase the cores for accumulation mode formation and increase the particle number concentration in accumulation mode. The accumulation mode particles could absorb the semi-volatile components and suppress the formation of nucleation mode particles. If the accumulation mode particles increase, the suppression of nucleation process becomes stronger, which lead to the lower number concentration of nucleation mode particles [19]. On the other hand, the higher oxygen content of methyl ester with shorter carbon chain length could improve the combustion process in locally rich diffusion combustion phase and aid in the oxidation of any newly formed soot, which could lead to decrease of large diameter particles in accumulation mode and increase of small diameter particles in nucleation mode, especially at high engine load. Additionally, viscosity and surface 
tension of methyl ester increase with carbon chain length, which could amplify the probability of hydrocarbons or unburned fuels condensed on the surface of large diameter particles.

The primary particle diameter distribution is analyzed using statistics based on the TEM images with software. The typical primary particle diameter distributions for different fuels are shown in Figure 10, which varies in the narrow range from10 to 60 $\mathrm{nm}$ at $2000 \mathrm{r} / \mathrm{min}$ and $0.68 \mathrm{MPa}$. Based on the figure, it could be concluded that the diameter of primary soot particle increases by carbon chain length.

\subsection{Effect of double bond of fatty acid ester}

The effect of double bonds in the methyl esters on the combustion and emission characteristics was investigated using the saturated methyl stearate (C18:0) and the monounsaturated methyl oleate C18:1). The results are shown in Fig. 11 for the combustion pressure and heat release rate, in Fig. 4 for the start of combustion and combustion duration. It can be observed that the monounsaturated methyl oleate prolongs the ignition delay and thus increases the peak combustion pressure and peak heat release rate, especially at high engine load. The ignition quality of a methyl ester is strongly affected by its level of unsaturation. Methyl ester with a higher level of unsaturation has a lower ignition quality than a saturated fatty acid ester [20]. The $\mathrm{C}=\mathrm{C}$ double bond in unsaturated methyl ester molecular could form stable allylic radicals through $\mathrm{H}$-atom transfer reaction, which could suppress the ignition ability [21]. With increase of unsaturation, the cetane number decreases, which leads to increase in ignition delay and increase in the fraction of premixed combustion. 
According to figure 5, the BSFC of unsaturated methyl ester is slightly higher than that of its saturated counterpart, due to the lower heat value of unsaturated methyl ester.

Fig. 12 and 13 show that compared with saturated methyl oleate, CO and HC decrease with the unsaturated methyl oleate, while NOx emission increases slightly and smoke opacity decreases at engine speeds of $1200 \mathrm{r} / \mathrm{min}$ and $2000 \mathrm{r} / \mathrm{min}$. Moreover, the effects of $\mathrm{C}=\mathrm{C}$ double bonds on emissions are more obvious at high engine load. At $0.68 \mathrm{MPa}$ engine load of $1200 \mathrm{r} / \mathrm{min}, \mathrm{HC}, \mathrm{CO}$ and smoke opacity decrease $3 \%, 50 \%$ and $18 \%$ from methyl stearate (C18:0) to methyl oleate (C18:1), while NOx increases $1.4 \%$ within the error measurements, while the variations of emissions are same with different engine speed. Unsaturated methyl ester molecules have lower cetane number and hence longer ignition delay. More fuel is burned in the premixed combustion stage, resulting in the increase of NOx emission and the reduction of $\mathrm{CO}$ and $\mathrm{HC}$ emissions. The viscosity of methyl oleate is lower than that of saturated counterpart, which could improve the atomization and fuel-mixing processes, leading to the lower $\mathrm{CO}$ and $\mathrm{HC}$ emission. In addition, the $\mathrm{C}=\mathrm{C}$ bond in unsaturated methyl esters could form $\mathrm{CH}$ and $\mathrm{C}$ radicals easier in region with relatively high fuel concentration. $\mathrm{CH}$ radical is an important factor to improve the formation of NOx. Moreover, adiabatic flame temperature increases with number of double bonds, leading to increase of the local reaction temperature, and thus increases the NOx emission [22]. There are two groups of factors to influence the soot formation of saturated and unsaturated methyl ester, fuel physical properties 
and chemical kinetics. In respect of physical influence, the lower cetane number and higher adiabatic flame temperature of unsaturated methyl ester could suppress the soot formation and improve soot oxidation. However, in respect of chemical kinetics, the unsaturated methyl ester consumption pathways lead to higher levels of $\mathrm{C}_{2} \mathrm{H}_{4}$, $\mathrm{C}_{2} \mathrm{H}_{2}$ and $\mathrm{CH}_{2}=\mathrm{CH}-\mathrm{CH}_{3}$, which are key species in the $\mathrm{C}_{3} \mathrm{H}_{3}$ formation resulting thus in higher soot precursors concentration than those of saturated counterpart [18]. Thus, in this experiment, the possible explanation for smoke opacity results compared between saturated and unsaturated methyl ester is that fuel physical properties are playing a slightly key role in the soot formation.

The effect of double bond of methyl ester on particle size distribution is shown in Fig. 14 and 15 for engine loads of $0.28 \mathrm{MPa}$ and $0.68 \mathrm{MPa}$ at engine speed of $1200 \mathrm{r} / \mathrm{min}$ and $2000 \mathrm{r} / \mathrm{min}$. As shown in figures, unsaturated methyl ester has slightly higher peak of the distribution curve. Moreover the particle number concentration in nucleation mode of unsaturated methyl ester is higher than saturated counterpart, while lower in accumulation mode, especially at high engine load. It can be seen that the smoke opacity of diesel fuel and saturated fatty esters is larger than that of unsaturated fatty ester due to large number concentration of accumulation mode particles in the range of $50 \mathrm{~nm}$ to $487 \mathrm{~nm}$ in diameter, especially at low engine speed and high engine load. As observed before, the main premixed combustion process occurs before top dead center (Fig. 4). The unsaturated fatty ester has higher cetane number than that of saturated one, leading to a larger fraction of premixed combustion. Moreover, the lower viscosity of unsaturated fatty ester could improve 
the atomization and form much smaller fuel droplet in combustion chamber. Combined with longer ignition delay of unsaturated fatty ester, the smaller atomized fuel droplets have longer time to mix with surrounding air, which lead to an increase of small diameter particles and a decrease of large diameter particles [19,23]. Additionally, the higher adiabatic flame temperature of unsaturated fatty ester could increase the local reaction temperature and then aid in the oxidation of newly formed soot particles. The typical primary particle diameter distributions for saturated and unsaturated methyl esters are shown in Figure 16 at 2000r/min and $0.68 \mathrm{MPa}$. According to the figure, the difference of primary particle diameter between saturated and unsaturated esters is quite moderate.

\subsection{Effect of carbon chain length in alcohol moiety}

The effect of carbon chain length in the alcohol moiety was studied using two fatty acid esters, namely, methyl oleate and ethyl oleate. The results are shown in Fig. 17 for the effect of alcohol chain length on the combustion characteristics and in Fig 4 on the start of combustion and combustion duration. It can be observed that the start of combustion is advanced and combustion duration is shortened with increase of carbon chain length in the alcohol moiety. Due to shorter ignition delay of ethyl oleate, the peak pressure and heat release rate are lower. According to Table 2, the cetane number of ethyl oleate is higher than that of methyl oleate, leading to the decrease of fuel burned in the premixed combustion mode and thus the lower peak pressure and heat release rate. According to figure 5, it is obvious that the BSFC of ethyl ester is higher than that of methyl ester, due to its lower heating value and 
earlier combustion.

The effects of alcohol chain length on the HC, CO, NOx and smoke emissions are shown in Fig. 18 and 19 at engine speeds of $1200 \mathrm{r} / \mathrm{min}$ and $2000 \mathrm{r} / \mathrm{min}$. It is observed that $\mathrm{HC}, \mathrm{CO}$ and smoke emission increase with the alcohol chain length, while NOx decreases slightly under most test modes. This phenomenon is more obvious at high engine speed of $2000 \mathrm{r} / \mathrm{min}$. At $0.68 \mathrm{MPa}$ engine load of $2000 \mathrm{r} / \mathrm{min}, \mathrm{HC}$, CO and smoke opacity increase $48 \%, 100 \%$ and $9 \%$ from methyl oleate (C18:1M) to ethyl oleate $(\mathrm{C} 18: 1 \mathrm{E})$, while NOx decreases $8 \%$. This may be attributable to the higher adiabatic flame temperature of methyl oleate than ethyl oleate [24]. Moreover, according to the combustion characteristics, the relatively higher fraction of premixed combustion of methyl ester increases the combustion temperature, which results in more complete combustion. Meanwhile, the oxygen content of methyl oleate is higher than that of ethyl oleate, leading to improvement in the oxidation and hence lower $\mathrm{HC}, \mathrm{CO}$ and smoke emissions. Moreover, methyl ester could have a higher rate of oxidation of soot in the flame due to its slightly higher adiabatic flame temperatures than that of ethyl ester. The sooting propensity correlates closely with the concentrations of $\mathrm{C}_{2} \mathrm{H}_{2}$ and $\mathrm{C}_{3} \mathrm{H}_{3}$, both being known as soot precursors, as well as the concentration of $\mathrm{C}_{2} \mathrm{H}_{4}$, a key species in the formation of $\mathrm{C}_{2} \mathrm{H}_{2}$. Ethylene can be produced from ethyl ester in the higher temperature environment during the combustion process, according to the reaction pathways (R1-R3) [25]. The higher $\mathrm{C}_{2} \mathrm{H}_{4}$ concentration in ethyl ester flames compared to methyl ester flames had also been found, which correlates well with higher sooting tendency of ethyl ester 
[18].<smiles>[R]C(=O)OCCC(=O)[C+]C=O</smiles>

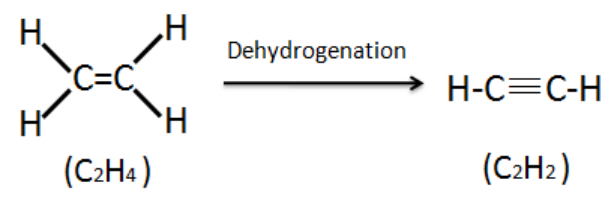

Fig. 20 and 21 show the particle size distribution of methyl ester and ethyl ester for engine loads of $0.28 \mathrm{MPa}$ and $0.68 \mathrm{MPa}$ at engine speeds of $1200 \mathrm{r} / \mathrm{min}$ and $2000 \mathrm{r} / \mathrm{min}$. It is obvious that, compared with methyl ester, ethyl ester generates lower number concentration in nucleation mode with diameter ranging from 10 to 50nm, while it has higher number concentration in accumulation mode, associated with higher smoke emission in Fig. 18-19. Moreover, this phenomenon is more obvious at low engine speed and high engine load. As discussed before, the lower fraction of premixed combustion of ethyl ester could reduce the small diameter particles and increase the large diameter particles than those of methyl ester. Moreover, ethyl ester is easier to form soot precursors, $\mathrm{C}_{2} \mathrm{H}_{4}$, during combustion process, which could improve the formation of primary soot particles in cylinder. These primary soot particles could agglomerate and grow up with the condensation 
of hydrocarbons during exhaust, leading to the increase of accumulation particle number concentration. The primary particle size distribution is statistically analyzed from TEM image as shown in figure 22 at $2000 \mathrm{r} / \mathrm{min}$ and $0.68 \mathrm{MPa}$. As seen in the figure, the primary particle size of ethyl ester is larger than that of methyl ester, which can validate the previous speculation that ethyl ester could improve the formation of primary soot particles in cylinder.

\section{Conclusion}

The effects of fatty acid chain length, number of double bonds and alcohol chain length on combustion and emission characteristics were investigated in this study with five individual fatty acid esters blended with diesel fuel in $40 \% \mathrm{v} / \mathrm{v}$ at two steady speeds and four engine loads. It can be concluded as follows:

(1) With increase of carbon chain length of $40 \%$ individual ester-diesel blends, the start of combustion advances and peak combustion pressure decreases. The BSFC of methyl esters with different carbon chain length maintain the same level. HC, CO and smoke emissions increase as carbon chain length especially at high engine load, while NOx decreases slightly. The particle number concentration of nucleation mode decreases and accumulation mode increases with carbon chain length. The diameter of primary particle increases by carbon chain length.

(2) The unsaturated methyl ester prolongs the ignition delay and increases the peak combustion pressure and peak heat release rate. The BSFC of unsaturated methyl ester is slightly higher than that of its saturated counterpart. The $\mathrm{C}=\mathrm{C}$ double bonds of unsaturated methyl ester are strongly correlated with $\mathrm{CO}, \mathrm{HC}$, nucleation mode 
and accumulation mode particles. The difference of primary particle diameter between saturated and unsaturated esters is quite moderate.

(3) With increase of alcohol moiety chain length in $40 \%$ individual ester-diesel blends, the start of combustion is advanced, leading to lower premixed combustion. The BSFC of ethyl ester is higher than that of methyl ester. $\mathrm{HC}, \mathrm{CO}$ and smoke emission increase with the alcohol chain length, while NOx decreases slightly under most test modes. Ethyl ester generates lower number concentration in nucleation mode, while have higher number concentration in accumulation mode. The primary particle size of ethyl ester is larger than that of methyl ester.

The above results indicate that molecular structure of fatty acid ester has great influence in combustion and emission characteristics. Thus, the composition of biodiesel could be modified and optimized during production process through new techniques or various feedstocks in order to improve combustion and emission of biodiesel.

\section{Acknowledgement}

The authors would like to thank National Science Foundation of China (Project No. 51306117; 51436005), State Key Laboratory of Engines (Tianjin University) and Foundation of Shanghai Jiao Tong University to support this research. 


\section{References}

[1] Giakoumis EG, Rakopoulos CD, Dimaratos AM, Rakopoulos DC. Exhaust emissions of diesel engines operating under transient conditions with biodiesel fuel blends. Prog Energ Combust Sci, 2012; 38: 691-715.

[2] Lapuerta M, Rodríguez-Fernandez J, García-Contreras R. Effect of a glycerol-derived advanced biofuel - FAGE (fatty acid formal glycerol ester)- on the emission of a diesel engine tested under the New European Driving Cycle. Energy, 2015; 93: 568-579.

[3] Zhu L, Cheung CS, Zhang WG, Huang Z. Combustion, performance and emission characteristics of a DI diesel engine fueled with ethanol - biodiesel blends. Fuel, 2011; 90: 1743-1750.

[4] Lapuerta M, Armas O, Rodríguez-Fernández J. Effect of biodiesel fuels on diesel engine emissions. Prog Energ Combust Sci 2008a; 34: 198-223.

[5] Yilmaz N, Vigil FM, Benalil K, Davis SM, Calva A. Effect of biodiesel-butanol fuel blends on emissions and performance characteristics of a diesel engine. Fuel 2014; 135: 46-50.

[6] Menkiel B, Donkerbroek A, Uitz R, Cracknell R, Ganippa L. Combustion and soot processes of diesel and rapeseed methyl ester in an optical diesel engine. Fuel 2014; 118: 406-415.

[7] Martinez G, Sanchez N, ENcinar JM, Gonzalez JF. Fuel properties of biodiesel from vegetable oils and oil mixtures. Influence of methyl esters distribution. Biomass Bioenergy 2014; 63: 22-32. 
[8] Westbrook CK. Biofuels combustion. Annu Rev of Phys Chem 2013; 64: 201-219.

[9] Jha SK, Fernando S, Filip To SD. Flame temperature analysis of biodiesel blends and components. Fuel 2008; 87: 1982-1988.

[10] Puhan S, Nagarajan G. Effect of biodiesel unsaturated fatty acid on combustion characteristics of a DI compression ignition engine. SAE 2008-28-0041.

[11] Lapuerta M, Armas O, Rodríguez-Fernández J. Effect of the Degree of Unsaturation of Biodiesel Fuels on NOx and Particulate Emissions. SAE 2008-01-1676.

[12] Salamanca M, Mondragon F, Agudelo JR, Benjumea P, Santamaria A. Variations in the chemical composition and morphology of soot induced by the unsaturation degree of biodiesel and a biodiesel blend. Combust Flame 2012; 159: $1100-1108$.

[13] Schönborn A, Ladommatos N, Williams J, Allan R, Rogerson J. The influence of molecular structure of fatty acid monoalkyl esters on diesel combustion. Combust Flame 2009; 156: 1396-1412.

[14] Pourkhesalian AM, Stevanovic S, Salimi F, Rahman MM, Wang H, Pham PX, Bottle SE, Masri AR, Brown RJ, Ristovski ZD. Influence of fuel molecular structure on volatility and oxidative potential of biodiesel particulate matter. Environ Sci Technol 2014; 48: 12577-12585.

[15] Kline SJ, McClintock FA. Describing uncertainties in single sample experiments. Mech Eng, 1953; 75: 3-8. 
[16] Ames WF, Cain G, Steele WG. Mathematics for mechanical engineers. Boca Raton, Fla.: CRC Press, 2000.

[17] Donkerbroek AJ, Boot MD, Liujten CCM, Dam NJ, Meulen JJ. Flame lift-off length and soot production of oxygenated fuels in relation with ignition delay in a DI heavy-duty diesel engine. Combust Flame 2011; 158: 525-538.

[18] Feng Q, Jalali A, Fincham AM, Wang YL, Tsotsis TT, Egolfopoulos FN. Soot formation in flames of model biodiesel fuels. Combust Flame 2012; 159: 1876-1893.

[19] Zhu L, Zhang WG, Liu W, Huang Z. Experimental study on particulate and NOx emissions of a diesel engine fueled with ultra low sulfur diesel, RME-diesel blends and PME-diesel blends. Sci Total Environ 2010; 408: 1050-1058.

[20] Ramírez-Verduzco LF, Rodríguez-Rodríguez JE, Jaramillo-Jacob AR. Prediction cetane number, kinematic viscosity, density and higher heating value of biodiesel from its fatty acid methyl ester composition. Fuel 2012; 91: 102-111.

[21] Hayes CJ, Burgess DR. Kinetic barriers of $\mathrm{H}$-atom transfer reaction in alkyl, allylic and oxoallylic radicals as calculated by composite ab initio methods. J.Phys. Chem 2009; 113:2473-2482.

[22] Ban-Weiss GA, Chen, JY, Buchholz BA, Dibble RW. A numerical investigation into the anomalous slight NOx increase when burning biodiesel: A new (old) theory. Fuel Process Technol 2007; 88:659-667.

[23] Pinzi S, Rounce P, Herreros JM, Tsolakis A, Dorado MP. The effect of biodiesel 
fatty acid composition on combustion and diesel engine exhaust emissions. Fuel 2013; 104: 170-182.

[24] Hellier P, Ladommatos N, Allan R, Rogerson J. The influence of fatty acid ester alcohol moiety molecular structure on diesel combustion and emissions. Energ Fuel 2012; 26: 1912-1927.

[25] Osswald P, Struckmeier U, Kasper T. Isomer-specific fuel destruction pathways in rich flames of methyl acctate and ethyl formate and consequences for the combustion chemistry of esters. J.Phys. Chem 2007; 111:4093-4101. 


\section{Figure captions}

Fig.1. Schematic diagram of experimental system

Fig.2. Molecular structure of tested fatty acid esters

Fig.3. Effects of carbon chain length on in-cylinder pressure and heat release rate at engine speed of $1200 \mathrm{r} / \mathrm{min}$

Fig.4. Effects of molecular structure on start of combustion and combustion duration at engine speed of $1200 \mathrm{r} / \mathrm{min}$

Fig.5. Effects of molecular structure on brake specific fuel consumption at engine speed of $1200 \mathrm{r} / \mathrm{min}$

Fig.6. Effects of carbon chain length on $\mathrm{HC}, \mathrm{CO}, \mathrm{NOx}$ and smoke emissions at engine speed of $1200 \mathrm{r} / \mathrm{min}$

Fig.7. Effects of carbon chain length on $\mathrm{HC}, \mathrm{CO}, \mathrm{NOx}$ and smoke emissions at engine speed of $2000 \mathrm{r} / \mathrm{min}$

Fig.8. Effects of carbon chain length on particle size distribution at engine speed of $1200 \mathrm{r} / \mathrm{min}$

Fig.9. Effects of carbon chain length on particle size distribution at engine speed of $2000 \mathrm{r} / \mathrm{min}$

Fig.10. Effects of carbon chain length on diameter of primary soot particle

Fig.11. Effects of double bond on in-cylinder pressure and heat release rate at engine speed of $1200 \mathrm{r} / \mathrm{min}$

Fig.12. Effects of double bond on $\mathrm{HC}, \mathrm{CO}, \mathrm{NOx}$ and smoke emissions at engine speed of $1200 \mathrm{r} / \mathrm{min}$ 
Fig.13. Effects of double bond on $\mathrm{HC}, \mathrm{CO}, \mathrm{NOx}$ and smoke emissions at engine speed of $2000 \mathrm{r} / \mathrm{min}$

Fig.14. Effects of double bond on particle size distribution at engine speed of $1200 \mathrm{r} / \mathrm{min}$

Fig.15. Effects of double bond on particle size distribution at engine speed of $2000 \mathrm{r} / \mathrm{min}$

Fig.16. Effects of double bond on diameter of primary soot particle

Fig.17. Effects of alcohol moiety chain length on in-cylinder pressure and heat release rate at engine speed of $1200 \mathrm{r} / \mathrm{min}$

Fig.18. Effects of alcohol moiety chain length on HC, CO, NOx and smoke emissions at engine speed of $1200 \mathrm{r} / \mathrm{min}$

Fig.19. Effects of alcohol moiety chain length on HC, CO, NOx and smoke emissions at engine speed of $2000 \mathrm{r} / \mathrm{min}$

Fig.20. Effects of alcohol moiety chain length on particle size distribution at engine speed of $1200 \mathrm{r} / \mathrm{min}$

Fig.21. Effects of alcohol moiety chain length on particle size distribution at engine speed of $2000 \mathrm{r} / \mathrm{min}$

Fig.22. Effects of alcohol moiety chain length on diameter of primary soot particle 


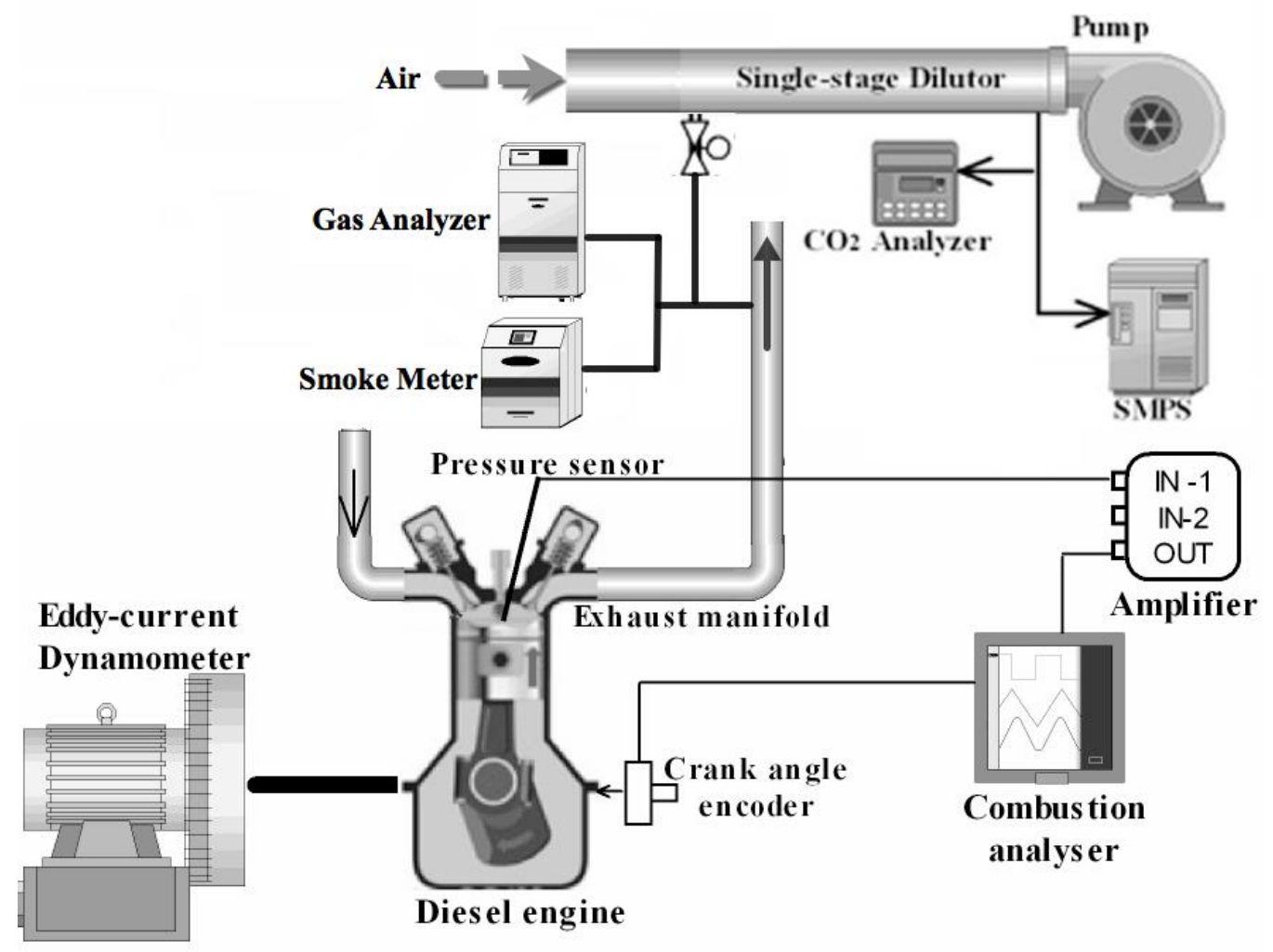

Fig. 1. 


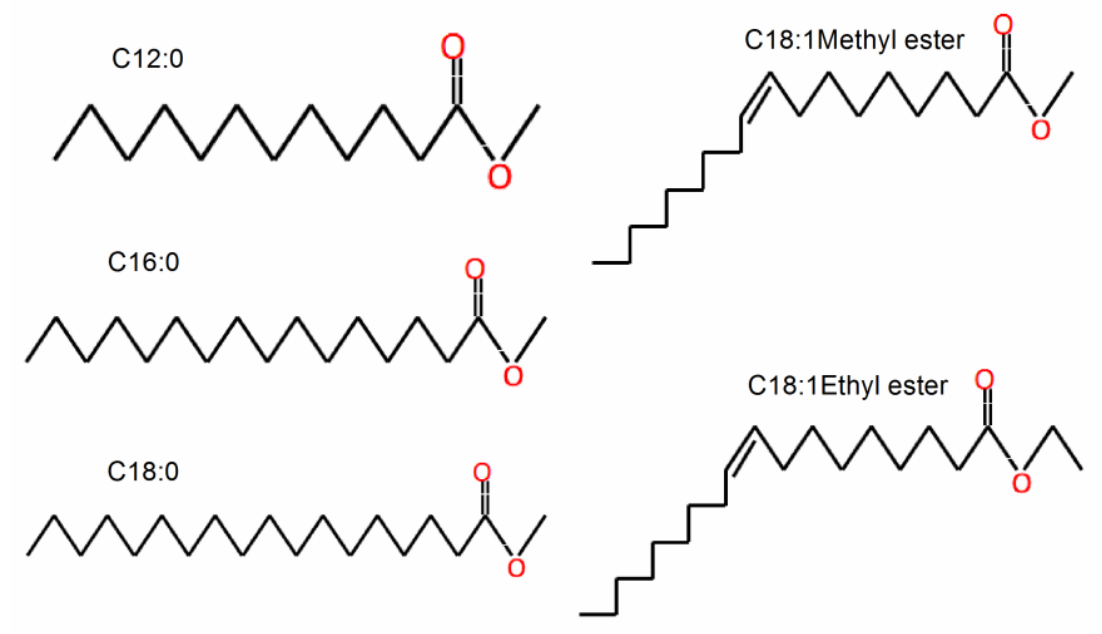

Fig. 2. 

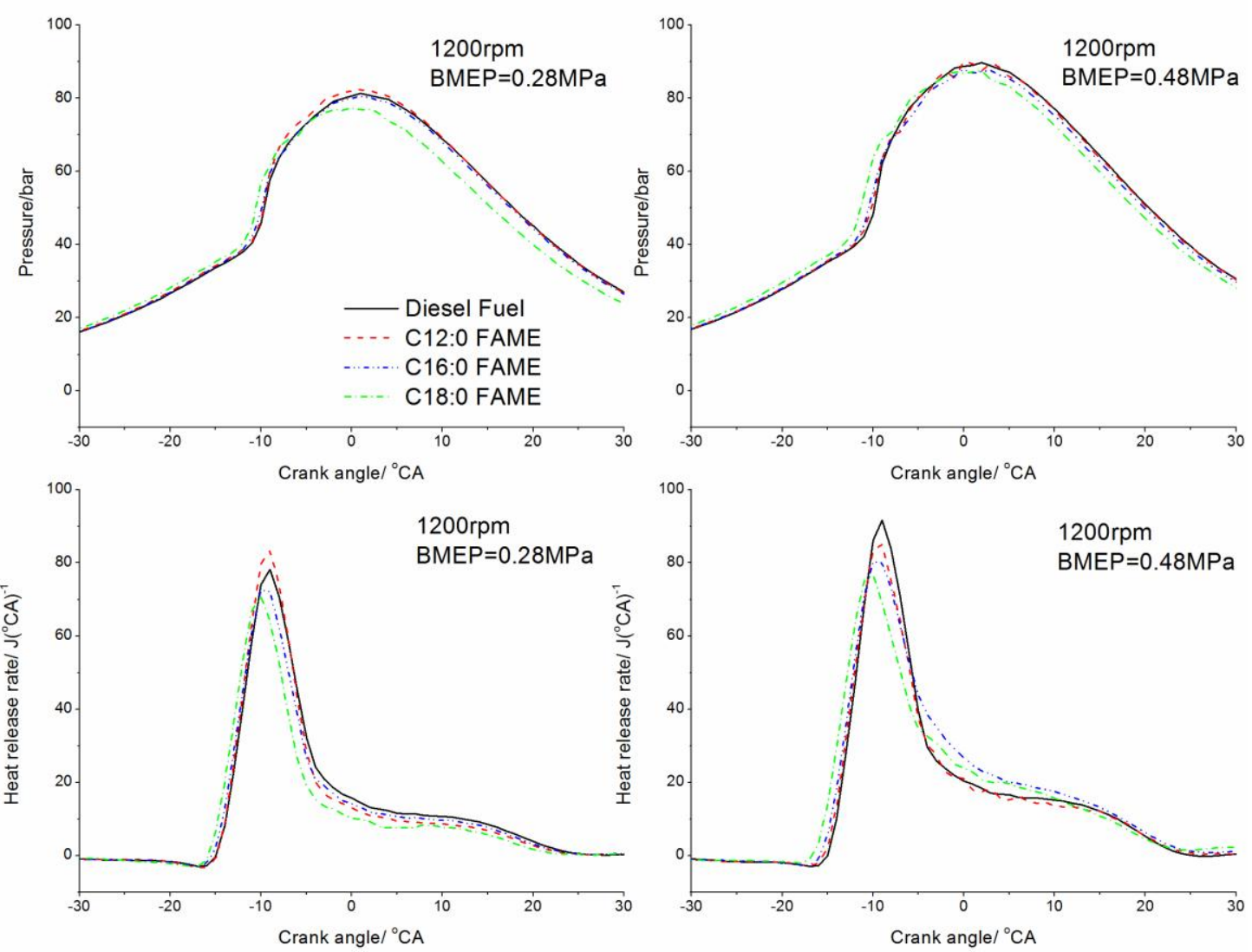

Fig. 3 

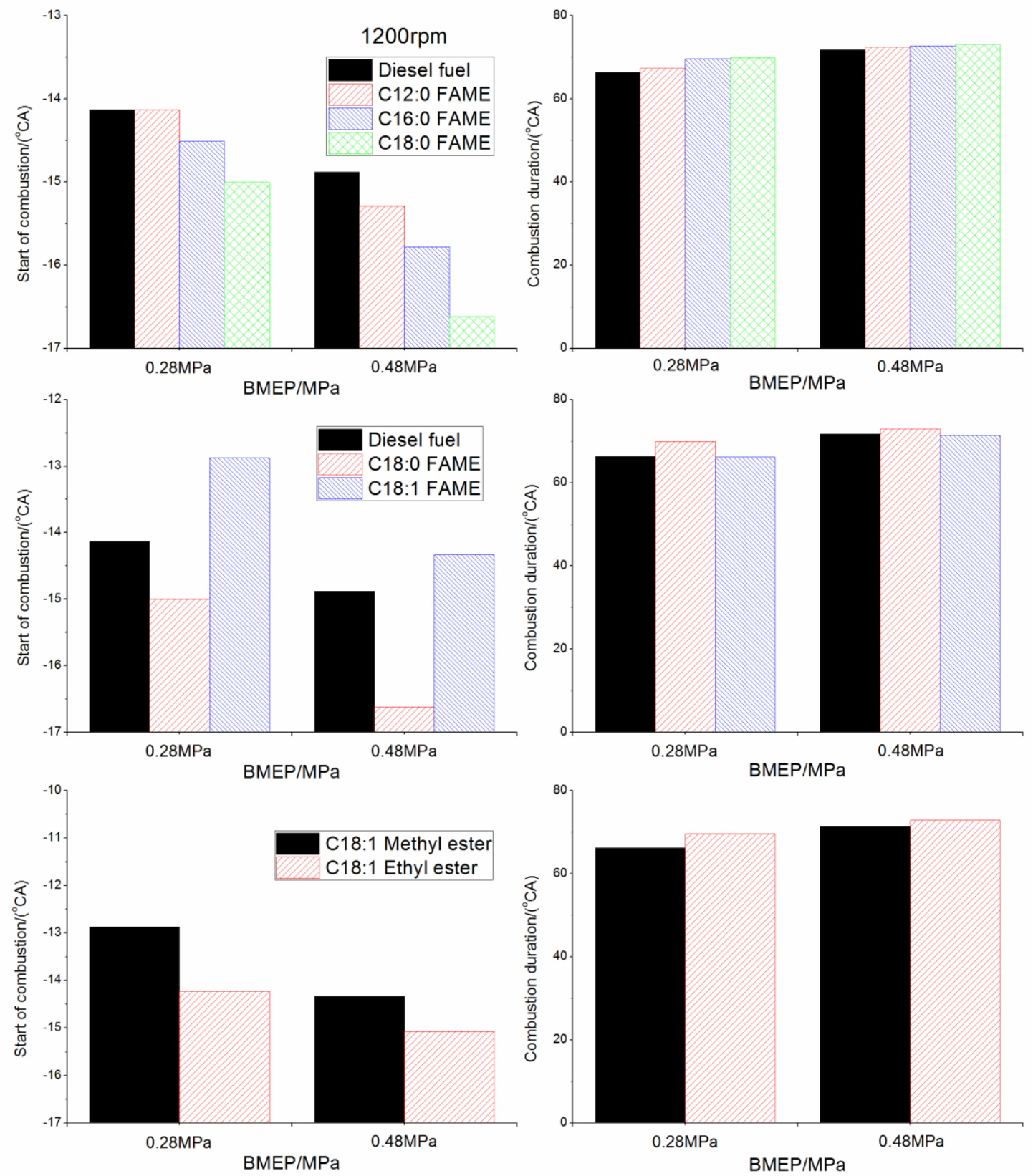

Fig. 4. 


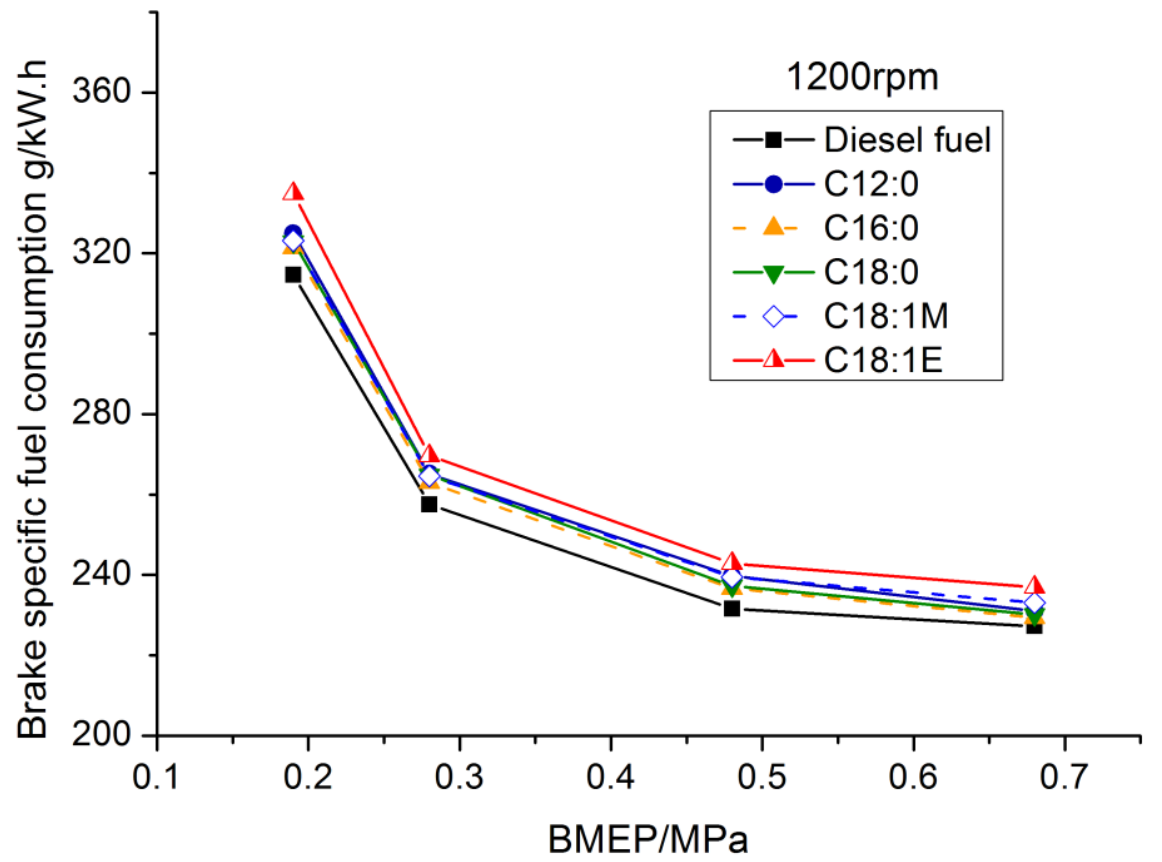

Fig. 5 

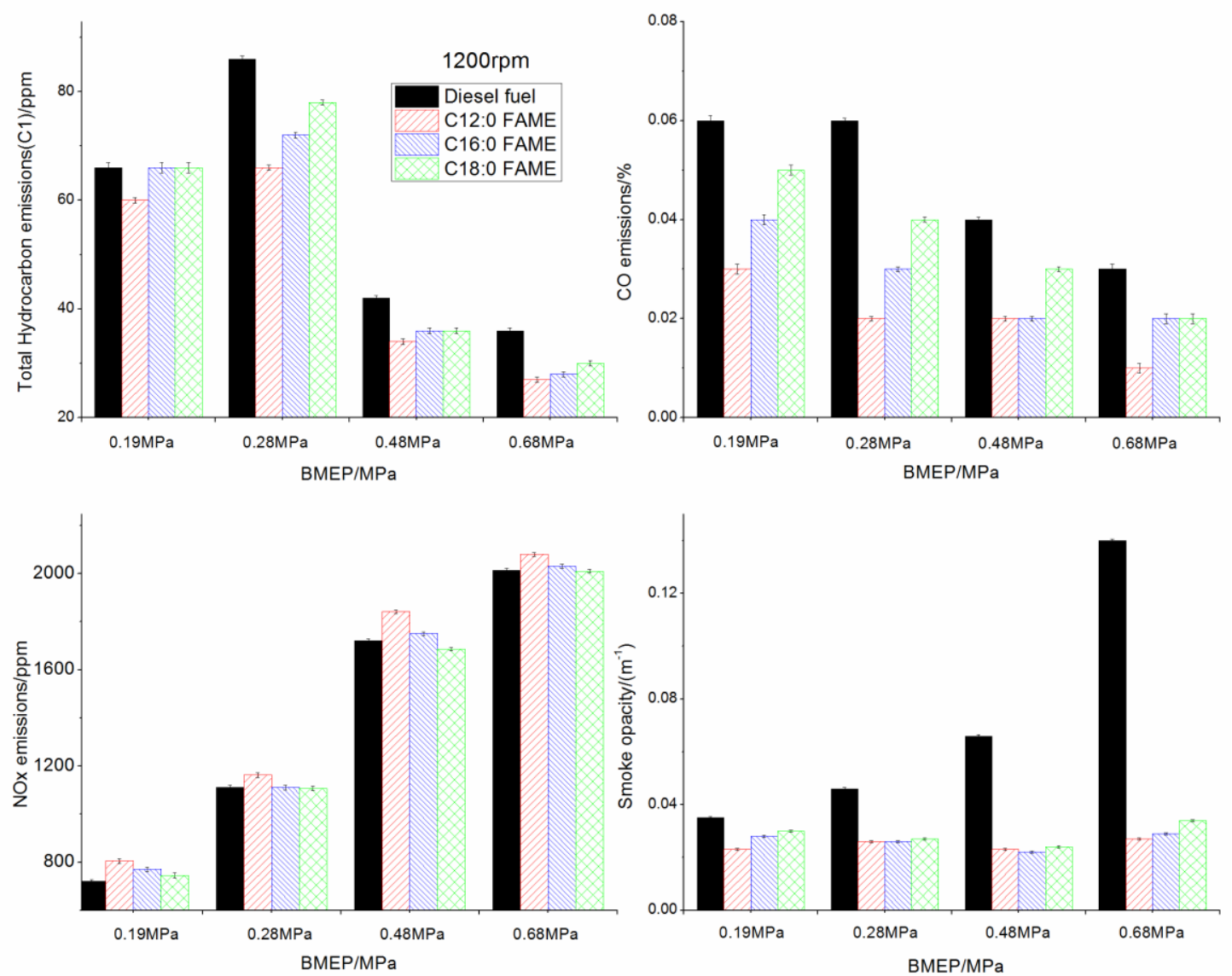

Fig. 6 

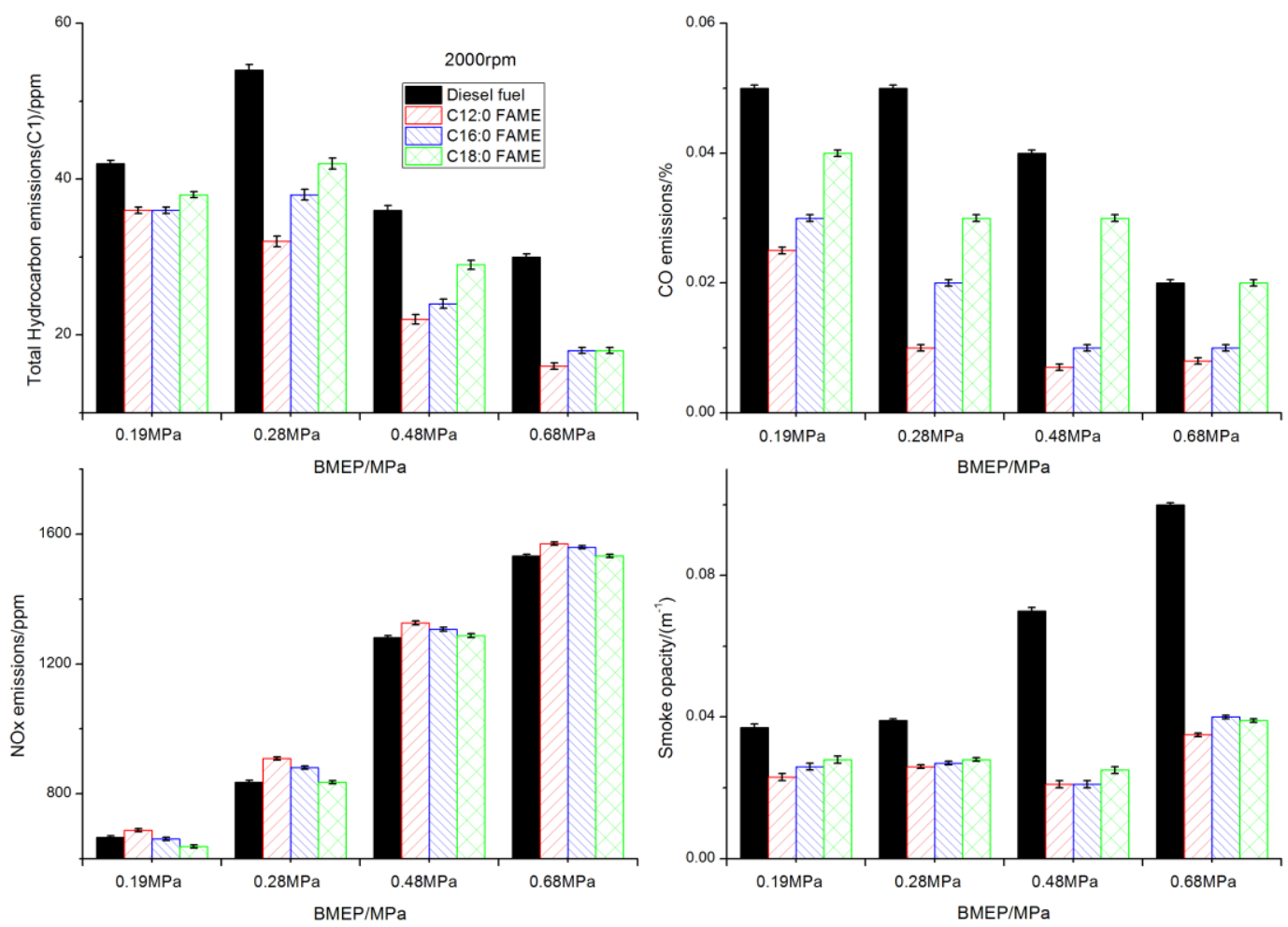

Fig.7. 


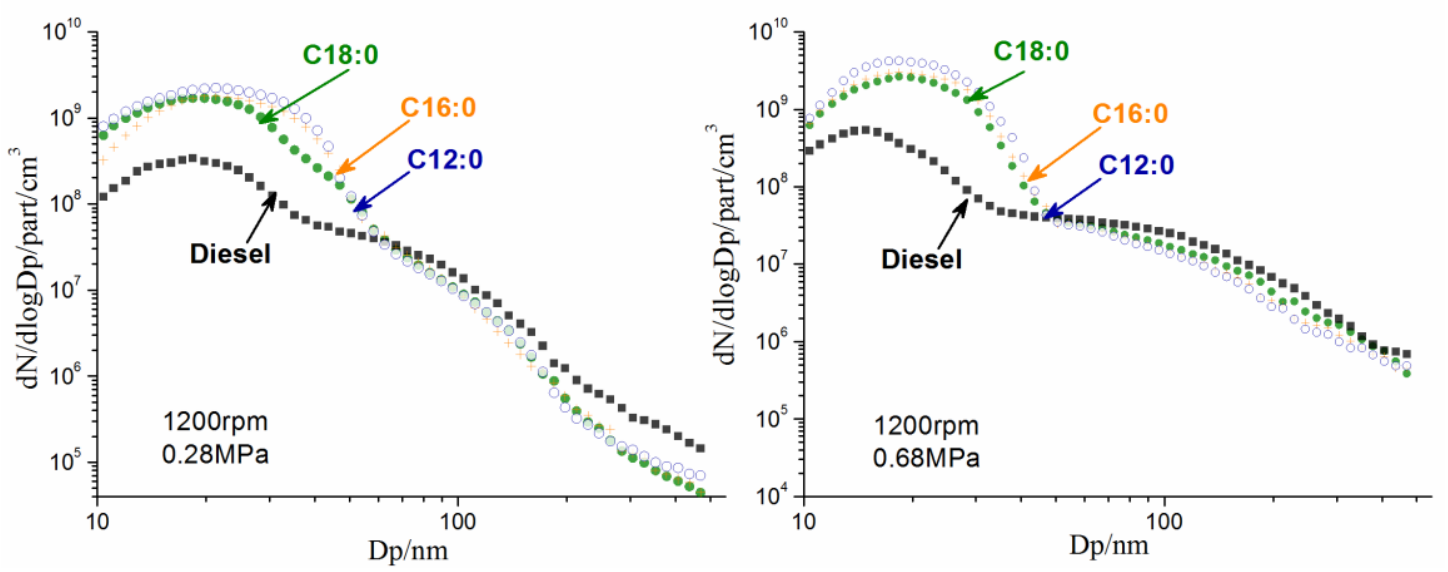

Fig. 8. 

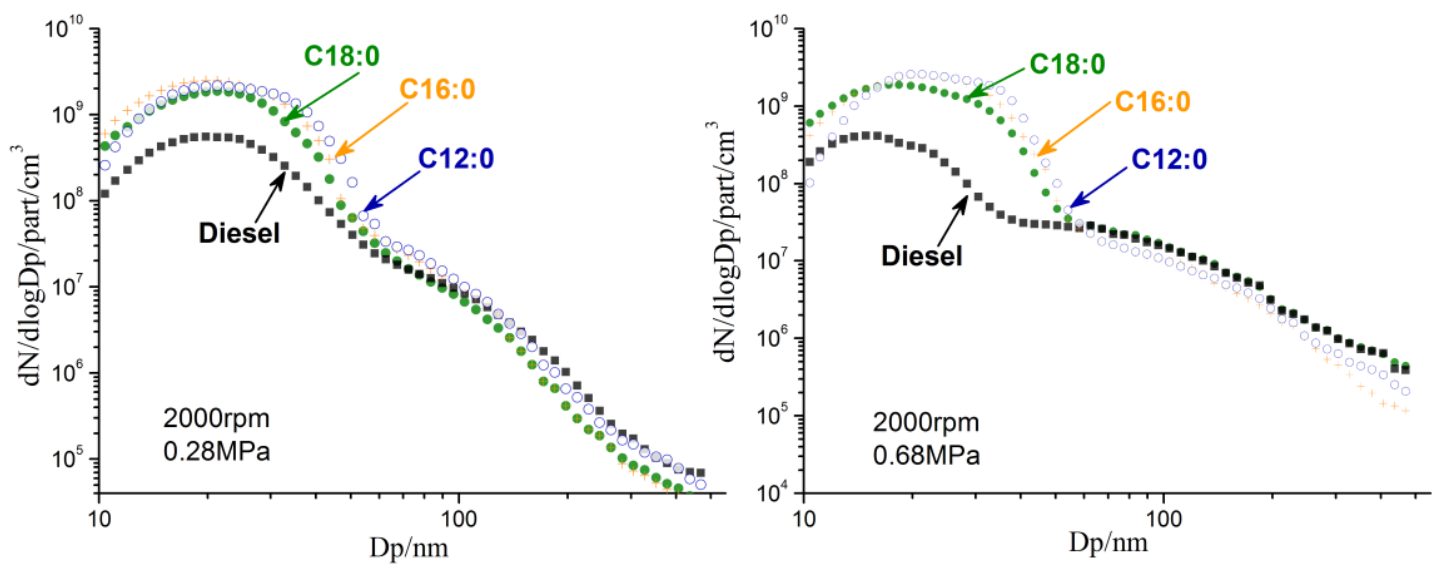

Fig. 9. 


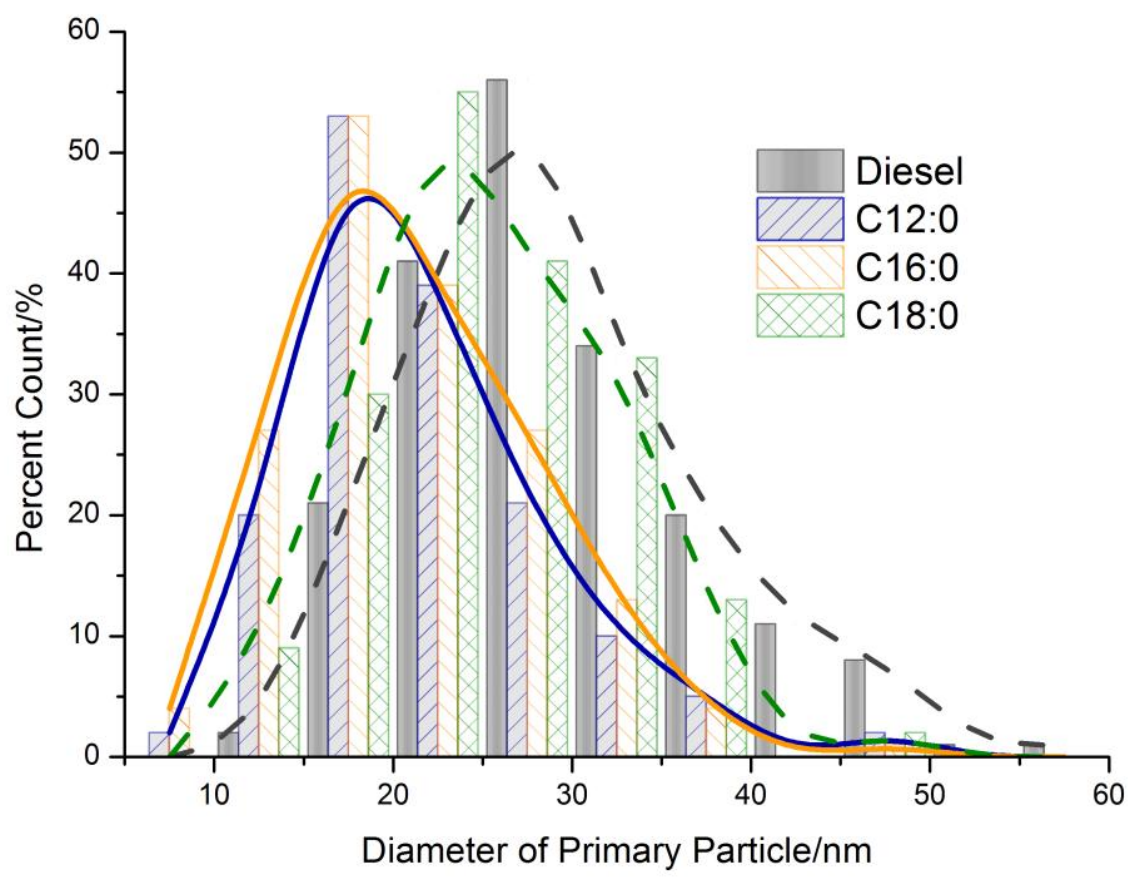

Fig. 10 . 

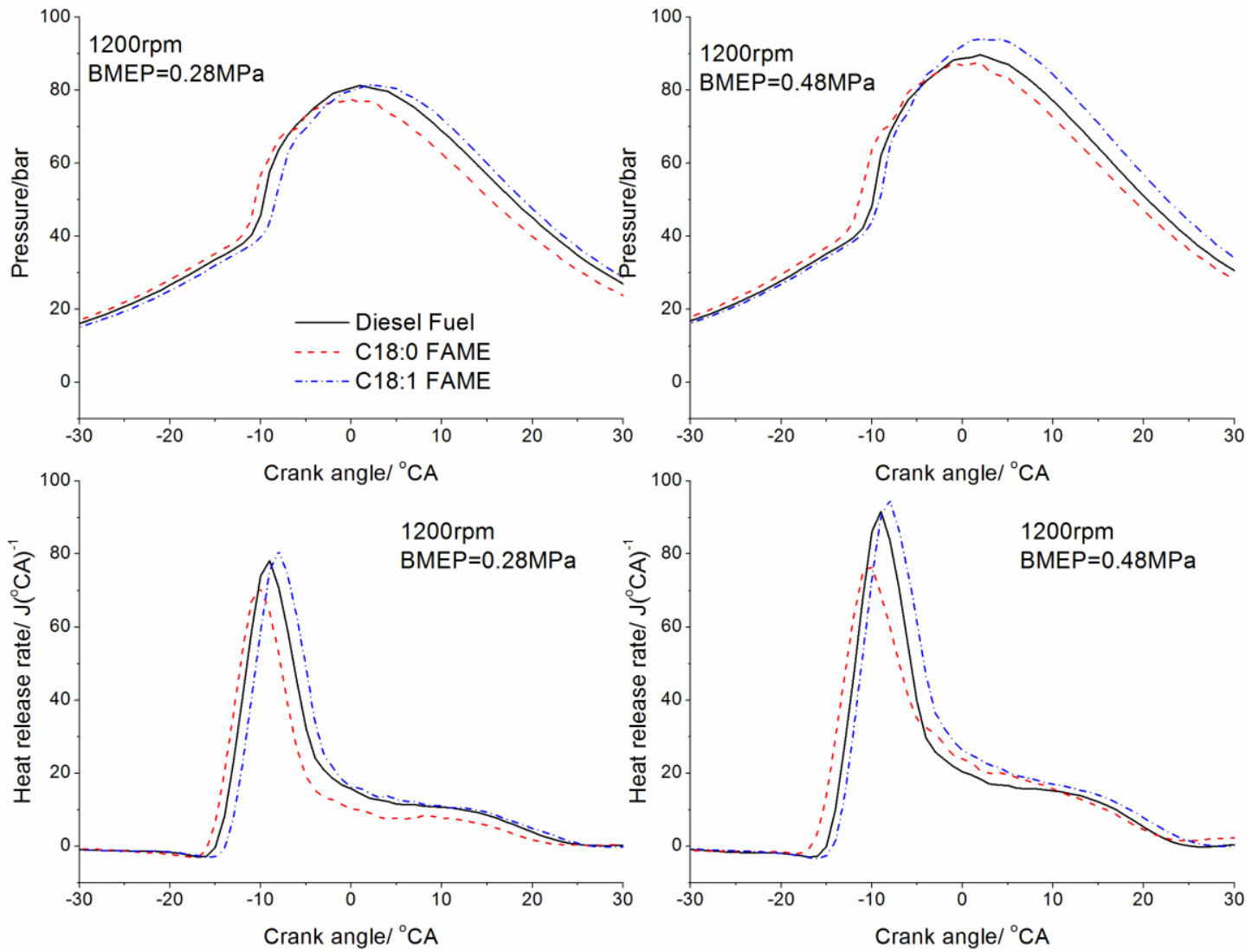

Fig. 11 

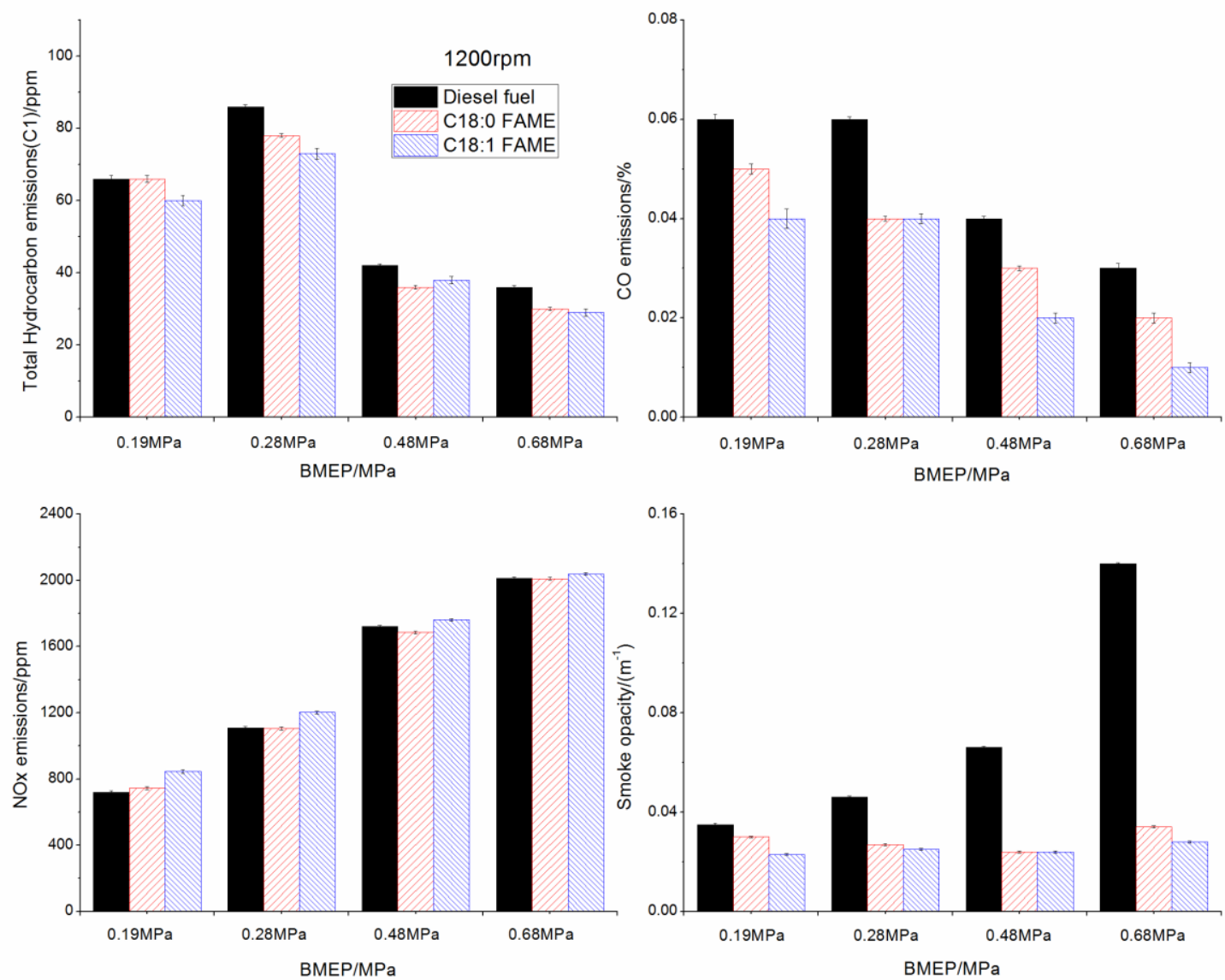

Fig. 12. 

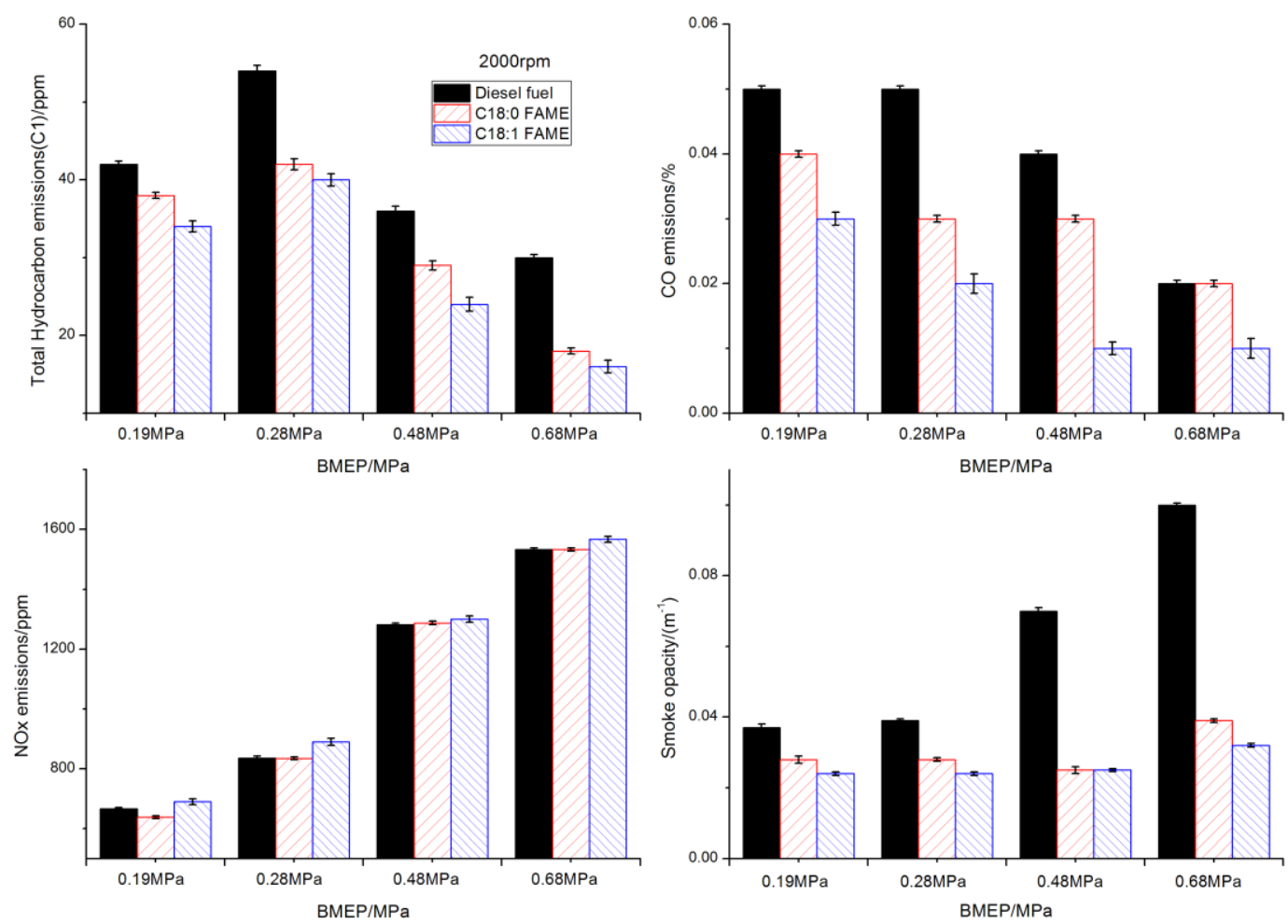

Fig. 13. 

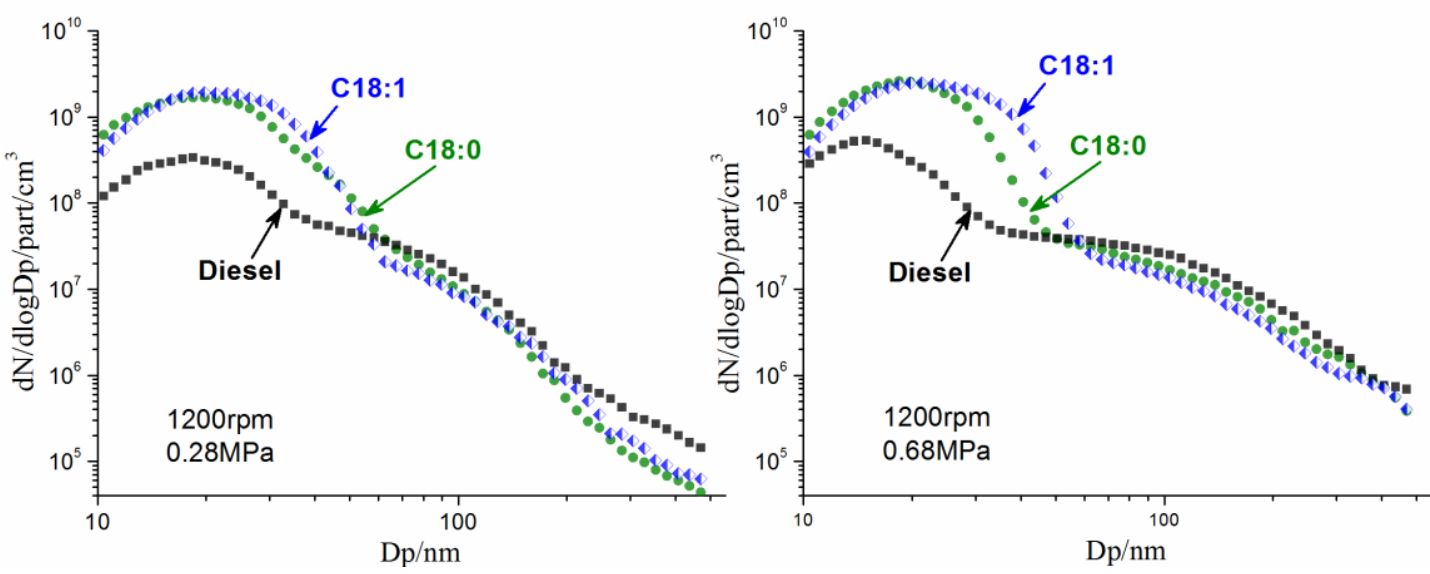

Fig. 14. 

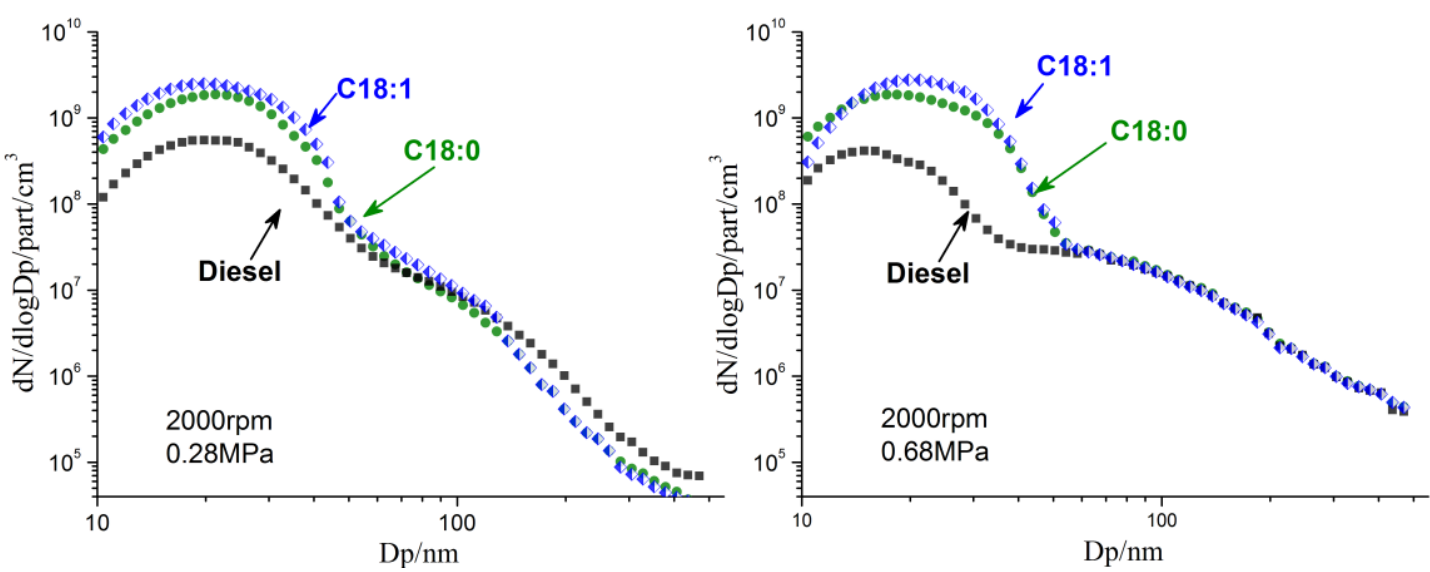

Fig. 15. 


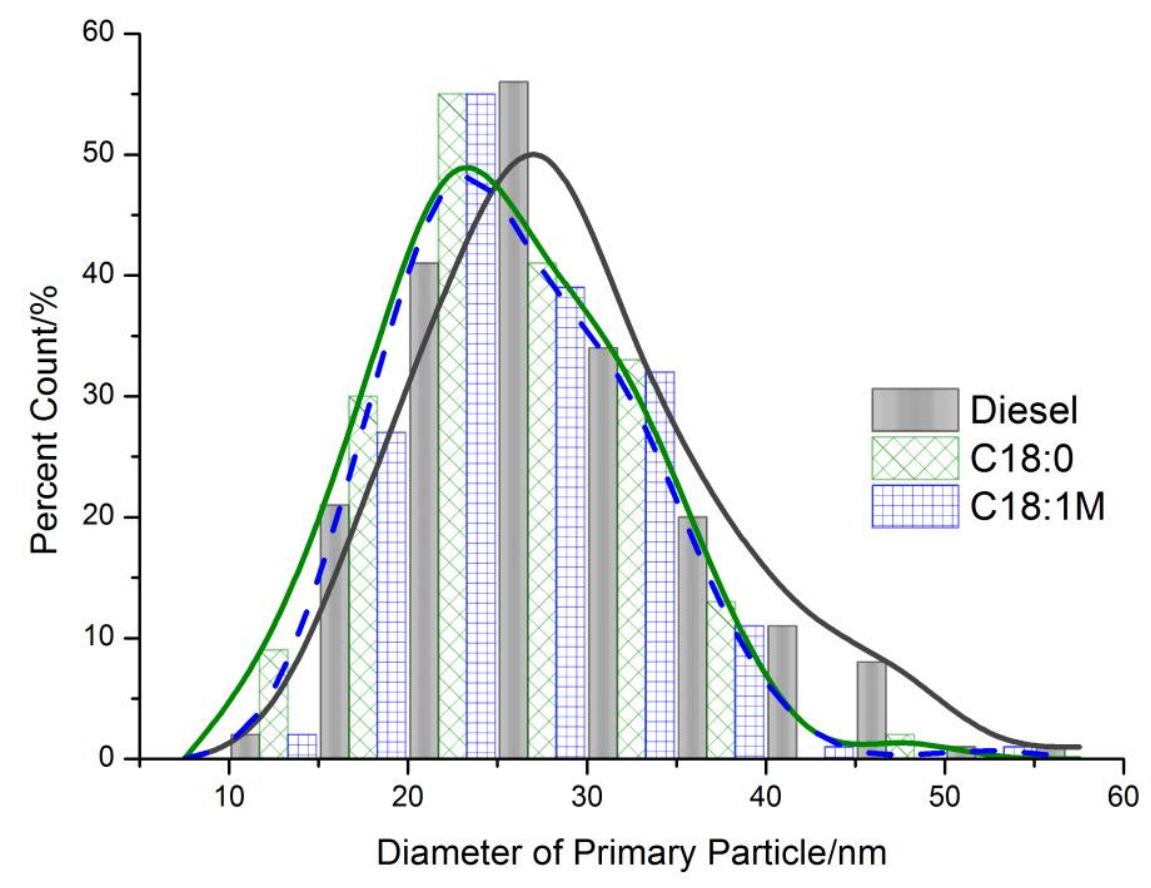

Fig. 16. 

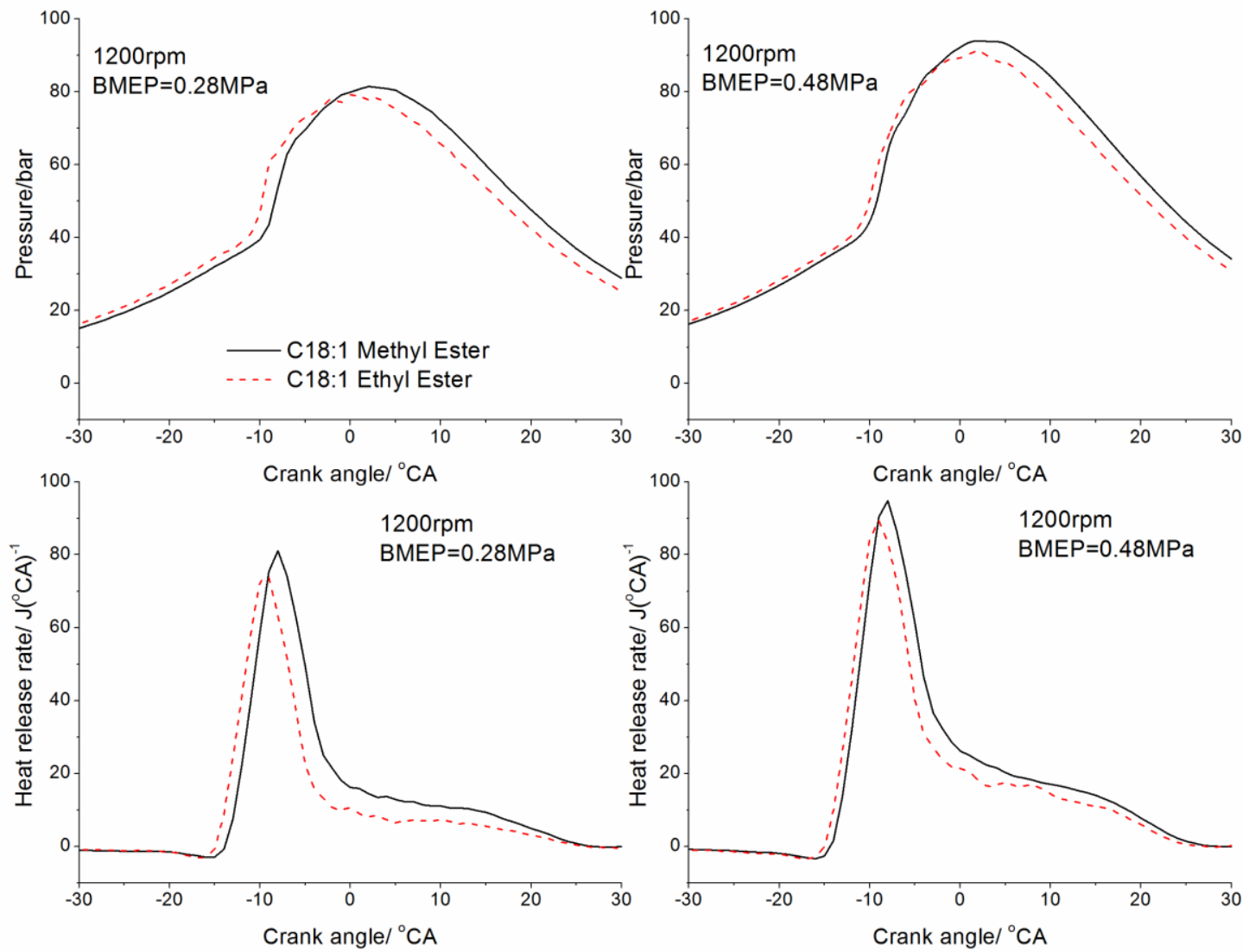

Fig. 17. 

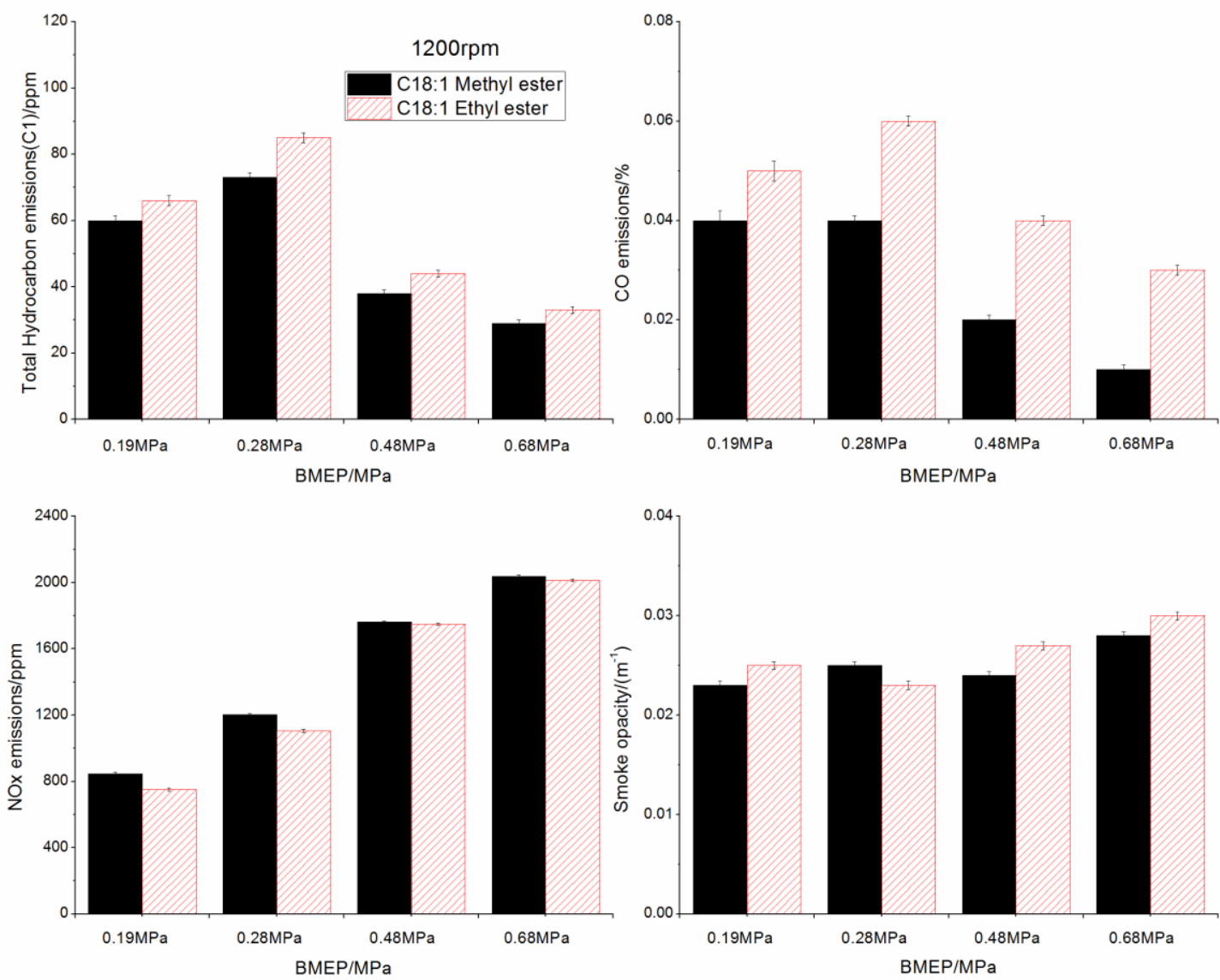

Fig. 18. 

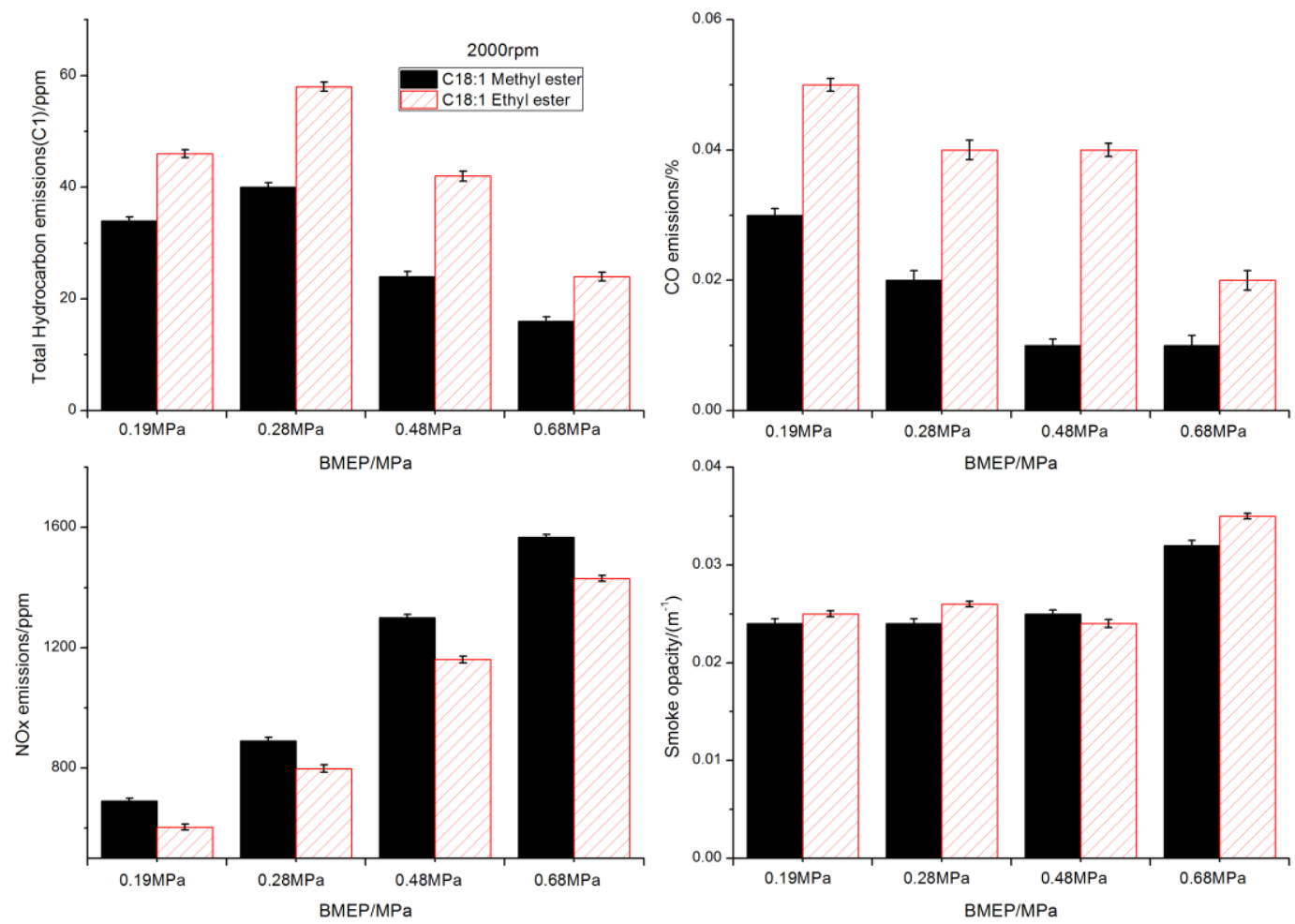

Fig. 19. 


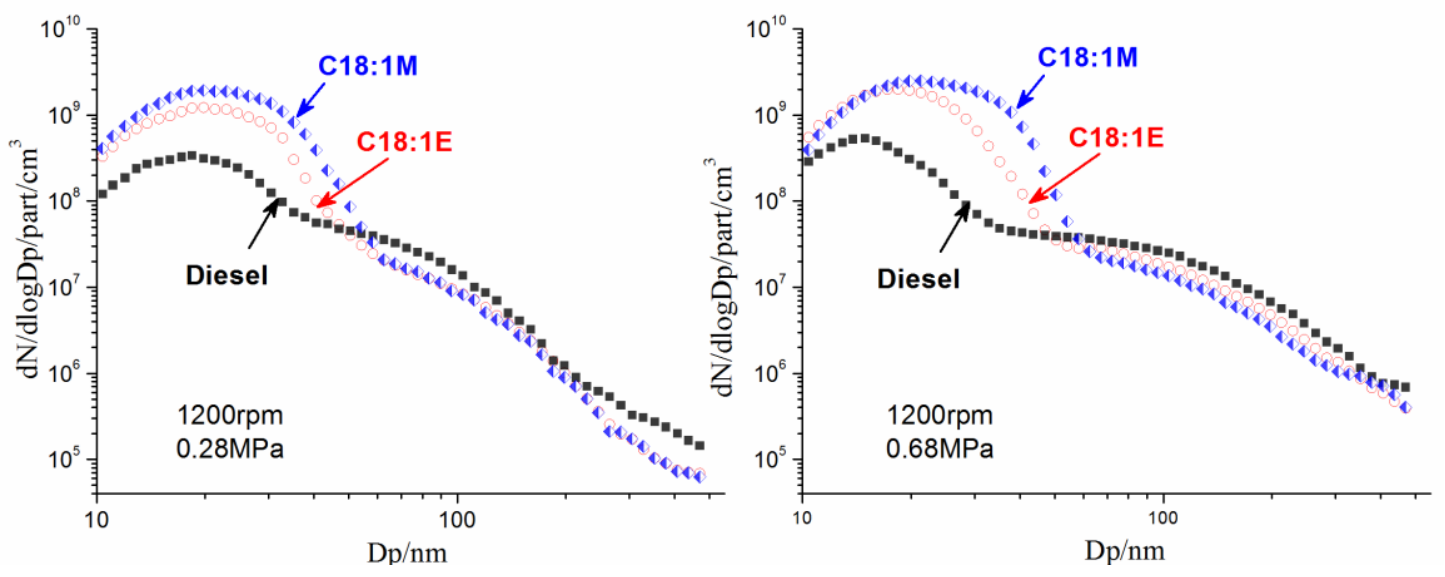

Fig. 20. 

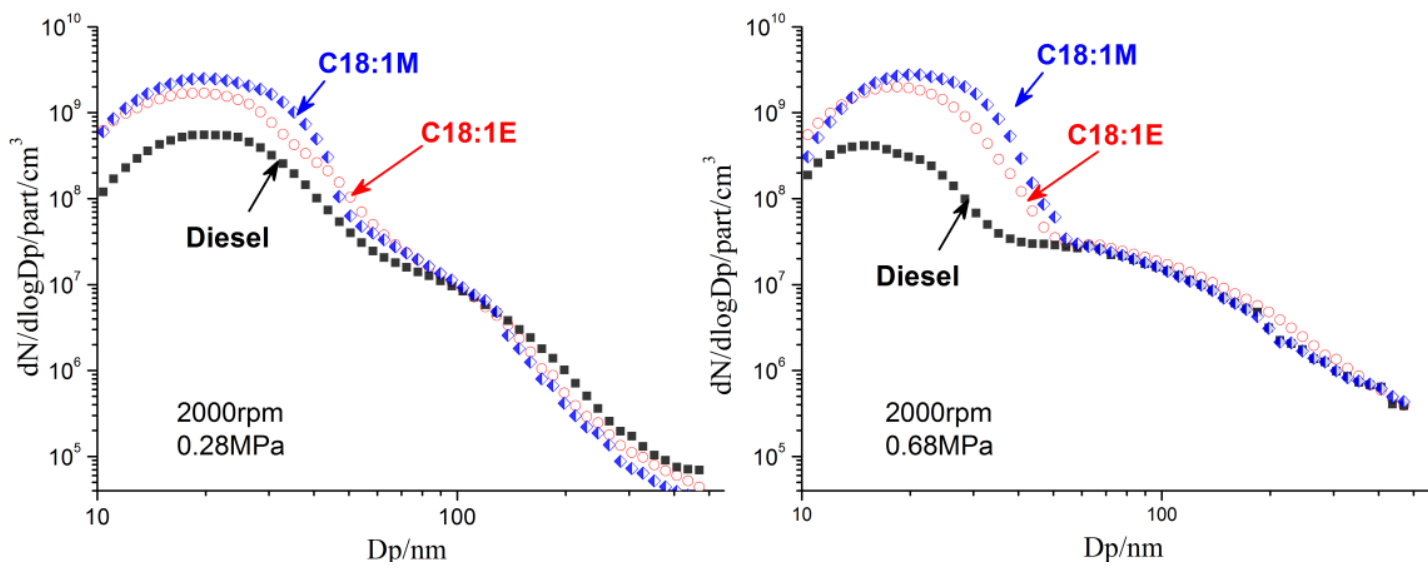

Fig. 21. 


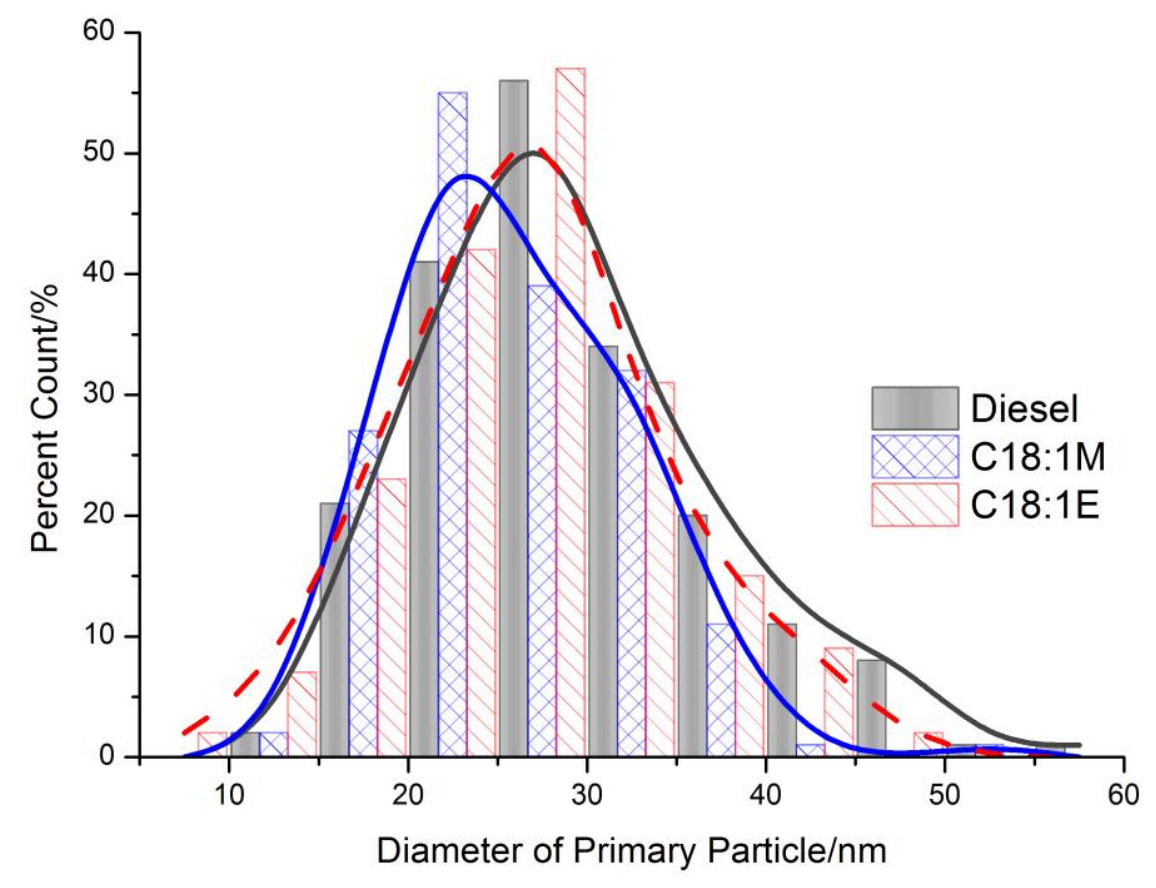

Fig. 22. 
Table 1 Engine specifications

\begin{tabular}{ll}
\hline Model & Cummins 4BTA \\
\hline Type & In-line 4-cylinder \\
Suction type & Turbo intercooler \\
Maximum power & $88 \mathrm{~kW} / 2800 \mathrm{rev} / \mathrm{min}$ \\
Maximum torque & $380 \mathrm{Nm} / 1600 \mathrm{rev} / \mathrm{min}$ \\
Bore x stroke & $102 \mathrm{~mm} \times 120 \mathrm{~mm}$ \\
Displacement & $3920 / \mathrm{cc}$ \\
Compression ratio & $17.5: 1$ \\
Injection pump type & In-line Bosch P7100 \\
\hline
\end{tabular}


Table 2. Fuel properties of $40 \% \mathrm{v} / \mathrm{v}$ fatty acid esters with diesel fuel

\begin{tabular}{|c|c|c|c|c|c|c|}
\hline & Diesel fuel & Methyl Laurate & Methyl Palmitate & Methyl Stearate & Methyl Oleate & Ethyl Oleate \\
\hline & & $\mathrm{C} 12: 0$ & $\mathrm{C} 16: 0$ & C18:0 & C18:1M & C18:1E \\
\hline Viscosity (mPa.s)@40 $\mathrm{C}$ & 2.6 & 2.322 & 3.178 & 3.669 & 3.165 & 3.647 \\
\hline Surface Tension $(\mathrm{mN} / \mathrm{m})$ & 26.7 & 35.5 & 37 & 37.9 & 37.3 & 37.2 \\
\hline Low heating value (MJ/kg) & 43.5 & 37.785 & 42.351 & 42.891 & 38.678 & 32.073 \\
\hline Density $\left(\mathrm{kg} / \mathrm{m}^{3}\right) @ 20^{\circ} \mathrm{C}$ & 0.84 & 0.873 & 0.8674 & 0.8684 & 0.8796 & 0.87 \\
\hline Oxygen content $(\mathrm{m} / \mathrm{m} \%)$ & 0 & 14.93 & 11.83 & 10.72 & 10.79 & 10.30 \\
\hline Cetane number*[18] & 52 & 62 & 81 & 89 & 62 & 65 \\
\hline
\end{tabular}

*Cetane number is referred from [18], which is the property of pure fatty acid esters. 